\title{
ATTITUDES OF THE TWELFTH GRADE STUDENTS TOWARDS THE USE OF COMPUTERS IN EDUCATION
}

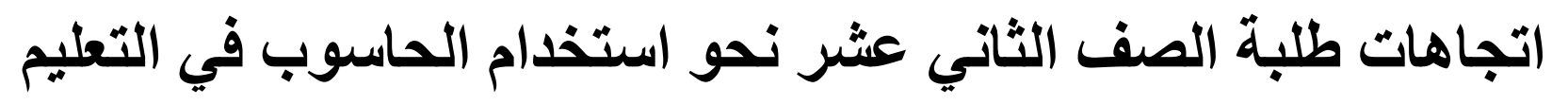

$$
\text { إسحاق بن سليمان بن ناصر العامري }
$$

\section{Ishaq Sulaiman Nasser Al-Amri ${ }^{1 *}$, Siti Rafiah Binti Abdul Hamid ${ }^{2}$, and Kamal J Badrasawi ${ }^{3}$}

${ }^{1} \mathrm{Ph} . \mathrm{D}$. Candidate at the Faculty of Education, International Islamic University Malaysia (IIUM): a.alaamri11@moe.om

${ }^{2}$ Assoc. Prof. Dr. at the Kulliyyah of Education, International Islamic University Malaysia (IIUM); srafiah60@iium.edu.my

${ }^{3}$ Asst. Prof. Dr. at the Kulliyyah of Education, International Islamic University Malaysia (IIUM); kamalbadrasawi@iium.edu.my

${ }^{*}$ Corresponding author

\begin{abstract}
This quantitative study discussed the students' attitudes towards the computers learning, the problem is; The existence of many obstacles that prevent students from benefiting from the computer learning, including Internet coverage and its strength, the need for training in computer tech and the presence of a tendency among some teachers to keep with traditional education. Therefore, the objectives of the study were: to diagnose the 12th graders' attitudes toward using the computer. And knowing the statistically significant differences in students' attitudes towards computer use due to their computer experiences, and receiving a previous course in it. The researcher adopted the descriptive analytical method. The study population consisted of (953) twelfth-grade students. The researcher chose a intended sample of (40) students. Then developed a questionnaire consisting of (44) items distributed in four fields. The data analyses were: a descriptive analysis was used to extract the averages, and $(\mathrm{T})$ test to determine the significance of the differences between the averages, and Pearson correlation coefficient was used for reliability. The findings revealed that: Student attitudes toward computer use have been positive at a high level. The first place was ranked "enjoyment while working on a computer", and the second came "fear and anxiety when using a computer", And their attitudes toward using the computer according to their previous experiences indicated: There is a difference of statistical significance for the benefit of those who studied a course in computers, and for the benefit of those who received a training course in computers.
\end{abstract}

Keywords: student attitudes, computer use, learning.

\section{الماخص}

ناقثت هذه الدر اسة الكمية اتجاهات الطلبة نحو استخدام الحاسوب في التعلم، تبرز مشكلة الدراسة من خلال؛ وجود معوقات كثيرة تحول دون استفادة الطلبة من الحأسوب في التعلم، منها تغطية الإنترنيت وقوته، الحاجة إلى التدربب على تقنيات الحاسوب، ووجود ميل لدى بعض المدرسين 


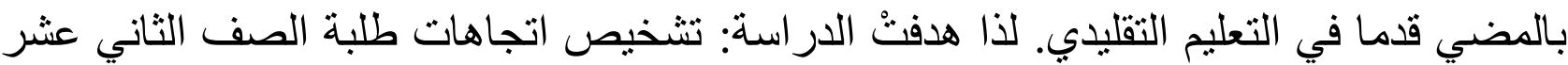
نحو استخدام الحاسوب. ومعرفة الفروق ذات الدلالة الإحصائية في اتجاهات الطلبة نحو استخدام

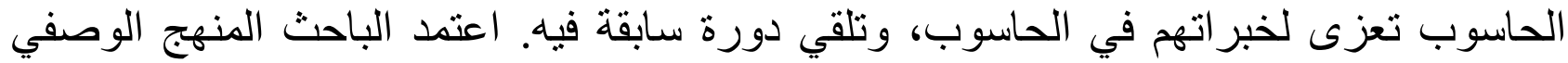
التحليلي. تكون مجتمع الدراسة من جميع طلاب الصف الثاني عشر البالغ عددهم (953)، اختار الباحث عينة مقصود بلغت (40) طالبا. طور الباحث استبانة تكونت من (44) فقرة موزعة على على

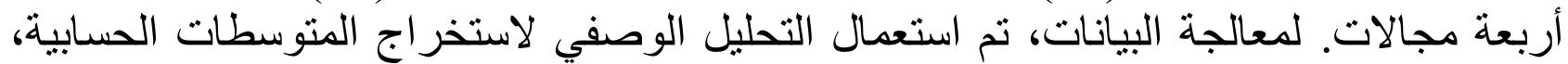
و اختبار (ت) لمعرفة دلالة الفروق بين المتوسطات، كما استخدم معامل ارتباط بيرسون للثبات.

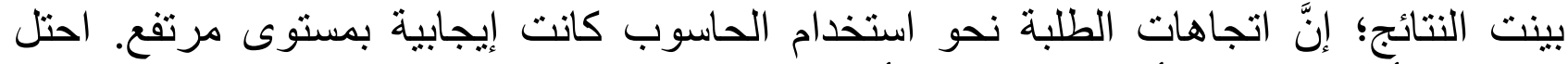
المركز الأول المجال الأول "الاستمتاع أثناء العمل على جهاز الحاسوب"، وجاء في المركز الثاني "الخوف والقلق عند استخدام الحاسوب". و إنَّ اتجاهاتهم نحو استخدام الحاسوب باختافلاف

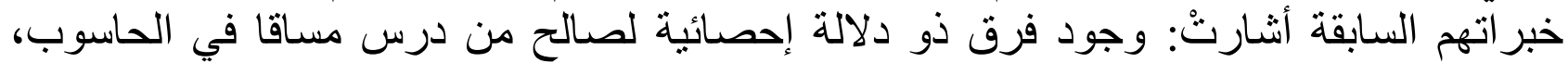
ولصالح من تلقى دورة تدريبية في الحاسوبه كلمات مفتاحية: اتجاهات الطلبة، استخدام الحاسوب، التعلم.

المقدمة

بدا الحاسوب يحتل مكانة هامة في التعليم في السنو ات الأخيرة ومع ذللك فان إدخاله بثكل فعال في

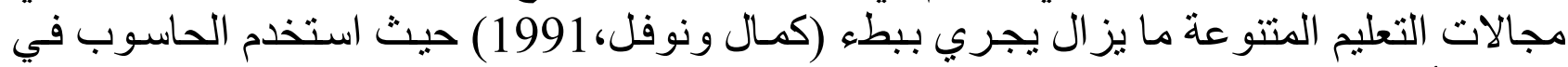

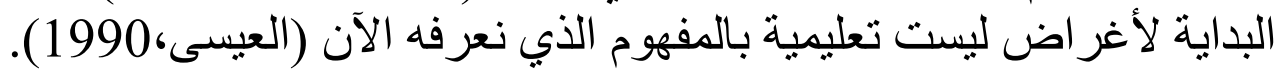
وقد تم إدخاله إلى المدارس باجتهادات فردية، ثم ما لبثت أنظـار المسؤولين عن التربيـة في أقطار من العـالم مثنل الو لايـات المتحدة وبريطانيـا وفرنسـا و أستر اليا و اليابـان لإدخالـه في التعليم (الحساج

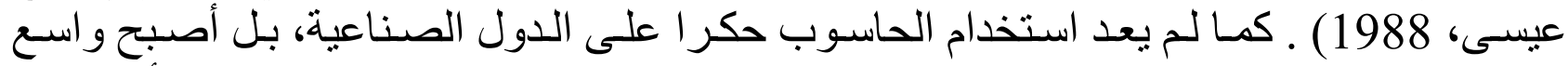
الانتشنار في الدول المتقدمة و الناميـة، إذ توسـع استخدمه ليشـمل جوانب الحيـاة المختلفة (أبو جـابر

و البداينة، 1989). ويمكن تصنيف الحاسوب حسب وظيفته في التعليم إلى نو عين رئيسيين هما:

- الحاسوب كعامل مساعد في العملية التعليمية (ACI) -

-

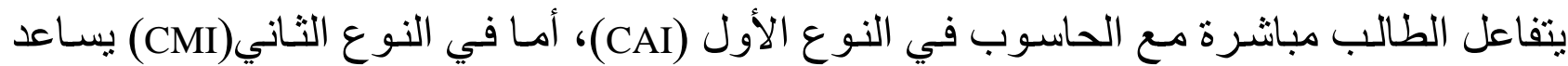

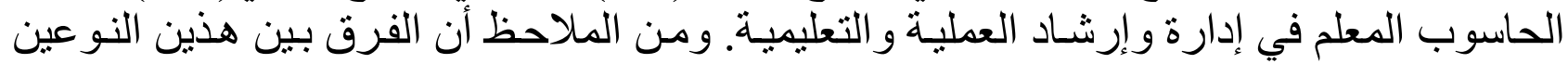

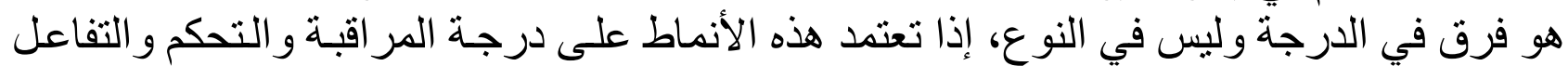
بين الطالب و الحاسـوب ( الفرا، 1985). وقد اقتر ح روكز (Rokars, 1981, p.16) ثلاثتة عثـرة

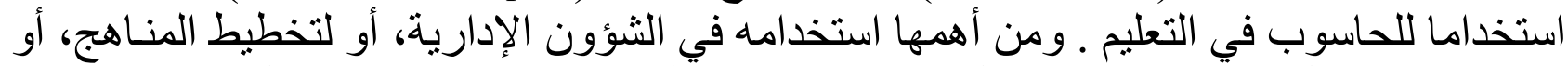
لتطوير المهنة، أو للمكتبة المدرسية أو للبحوث العلمبـة أو للامتحانـات المدرسية أو الإدارة علمبـة الإنة التدريس ......... الخ.

و عليه يمكن التصنيف استخدامات الحاسوب في المؤسسـة التربويـة في احد المجـالات التاليـة كمـا

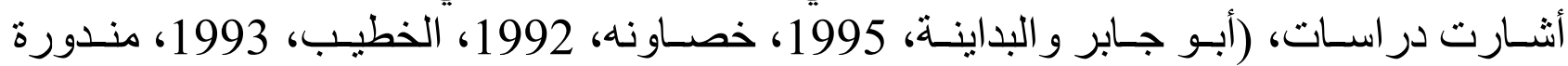
ورحاب، 1989، الهادي، 1995): 


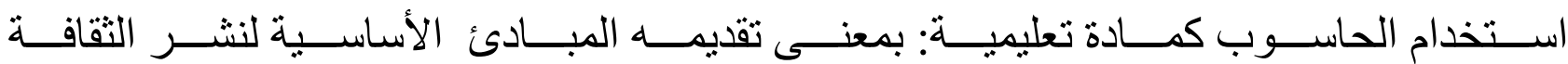

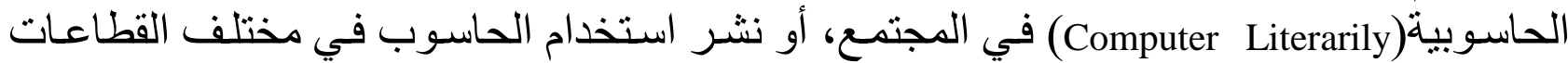
المهنية بهدف تطوير تطبيقات الحاسوب و الاستفادة منه.

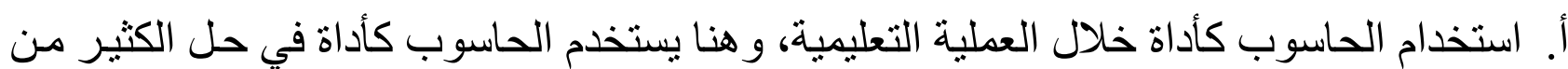

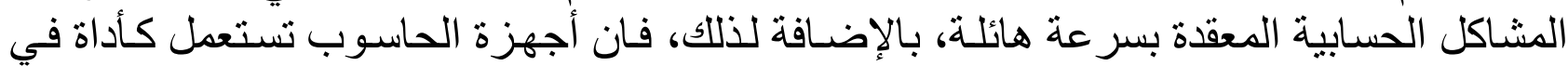

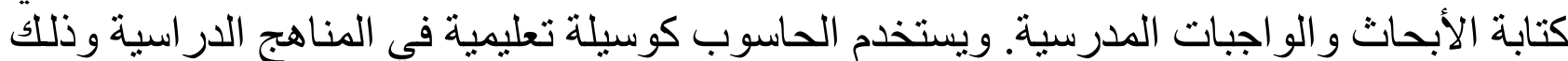

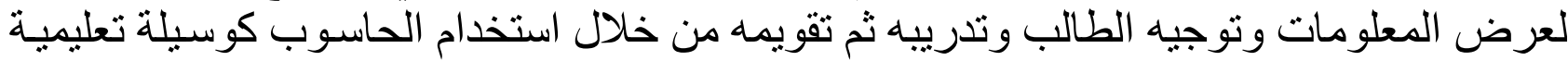

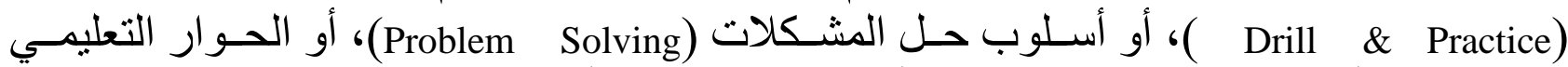

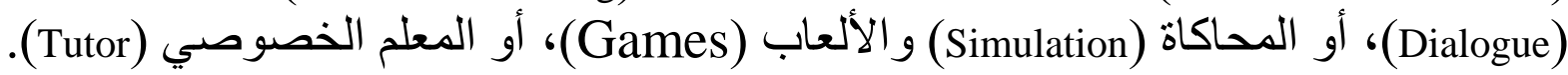

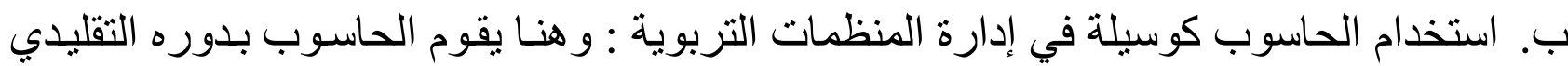

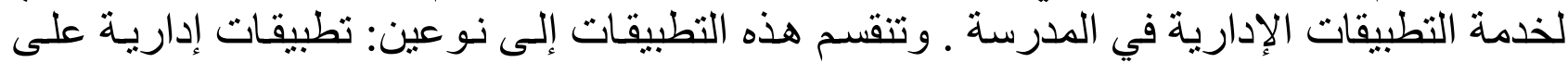

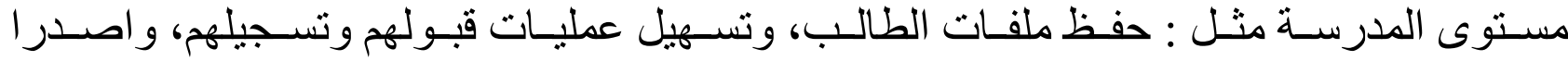
الثهادات، وتطبيقات على مستوى الصف، مثل عمل التقارير، و الامتحانات، و التخطيط للارس.

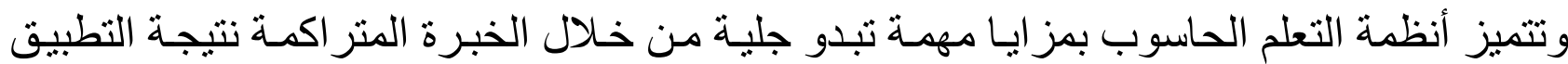

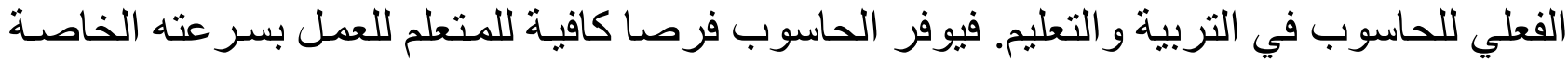

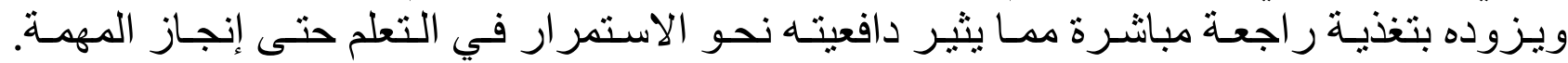

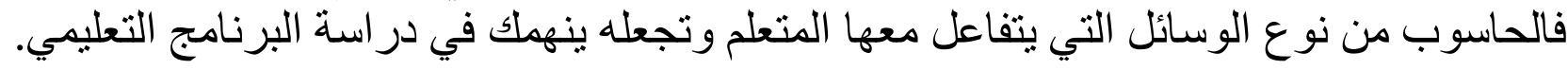

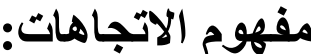

تعـد الأسـرة النواة الأساسـية في تشـكيل اتجاهـات الفرد و العامـل الرئيسـي مـن عو امـل التنشـئة

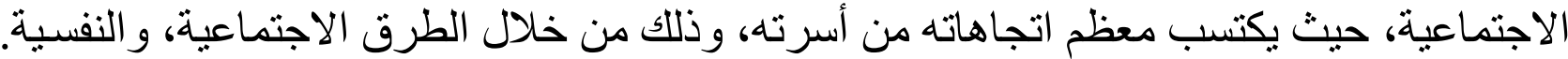
وقد حظي موضوع الاتجاه بمكانة بارزة و هامة في علم النفس ويشير سنايدر (Schneider , 1988)

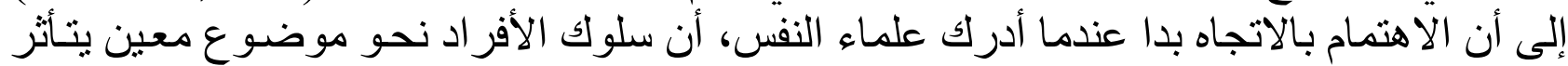

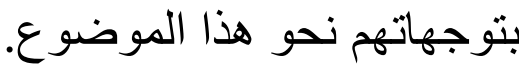
ويؤكد مرعي وبلقيس (1984) أن "أول من استخدم مصطلح الاتجاه كان الفيلسوف الإنجليزي

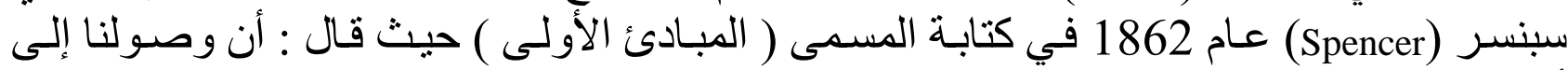

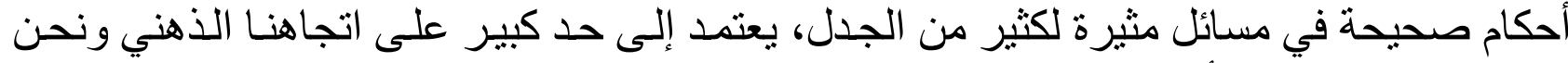
نصغي إلى هذا الجدل أو نشارك فيان.

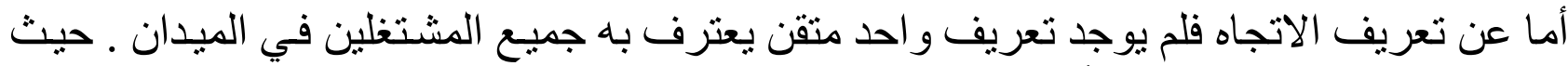

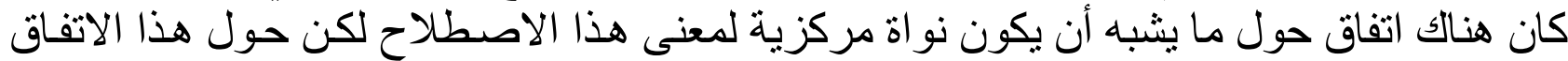

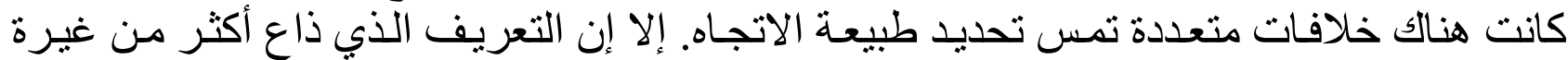

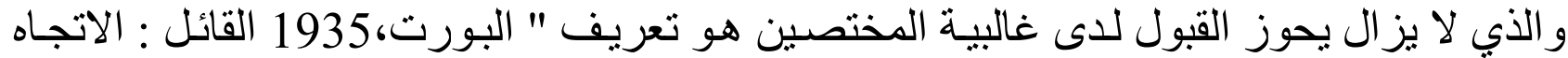

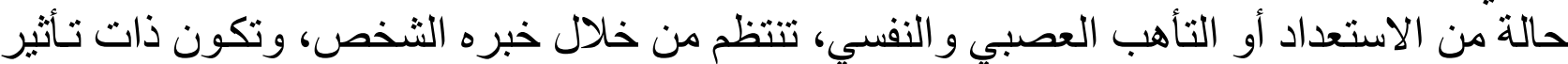

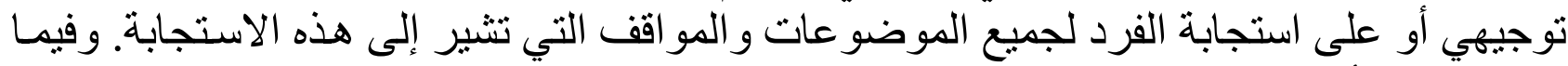
يلي عرض لأبرز تعريفات الاتجاه.

حدد إسماعيل وآخرون (1967) : الاتجاه على انه مفهوم يصدر عن محصلة استجابات الفرد نحو 


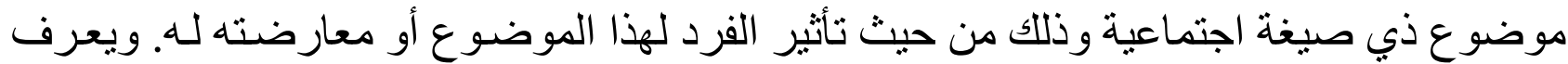

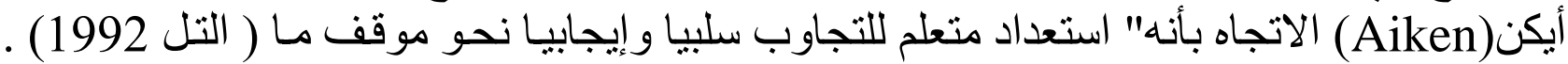

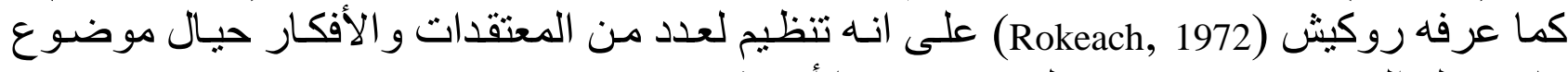

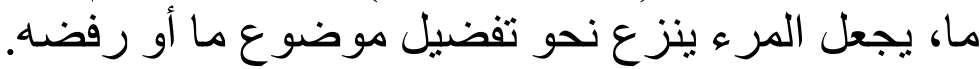

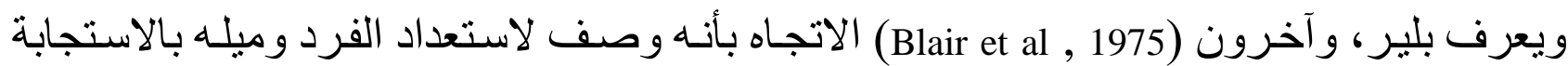

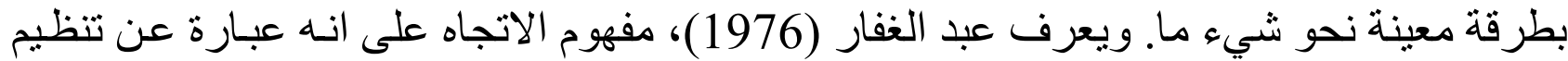

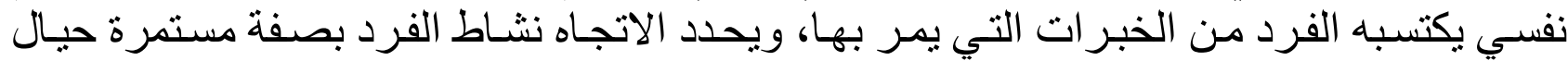

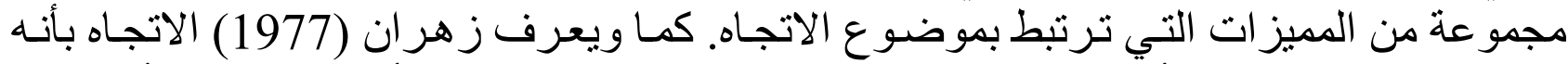

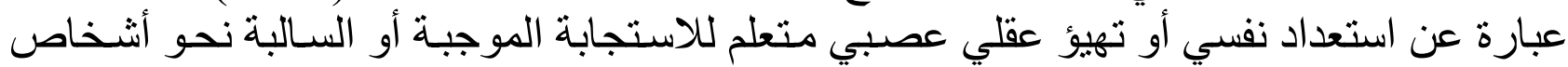

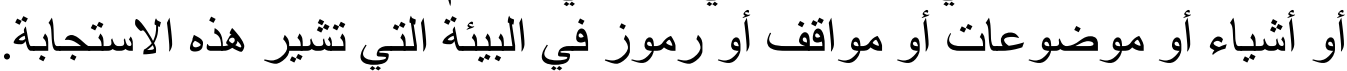

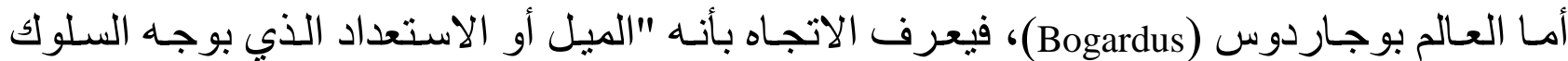

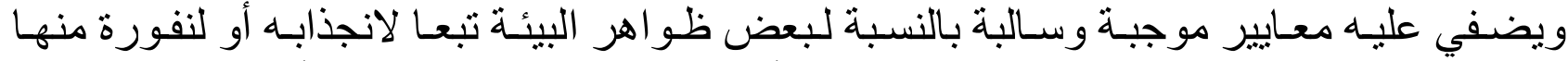

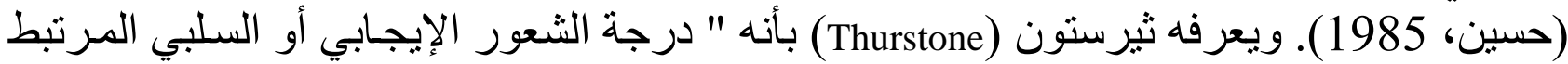

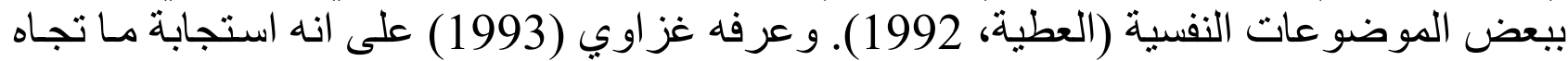

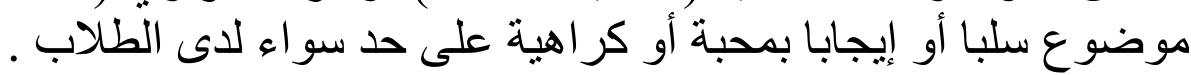

مشكلة الدراسة مونة

تبرز مشكلة الدر اسة من خلال تشعب مجالات استخدام الحاسوب، فقد تمت الإفادة من الحاسوب إنهاب

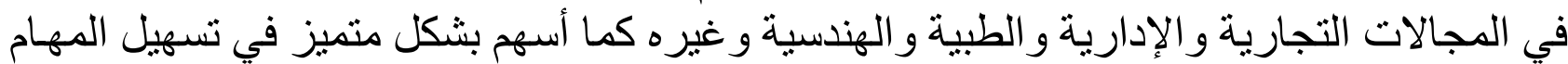
و الأعمال في مجالات الحياة العلمية و المنزلية ولية والية اليومية.

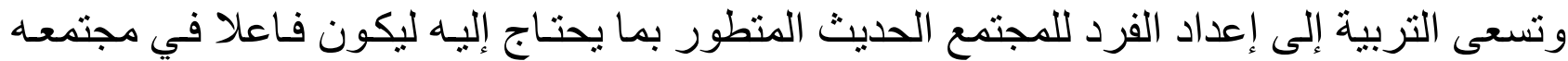

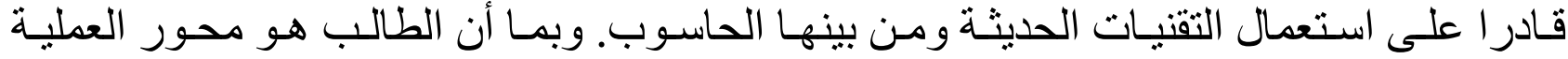

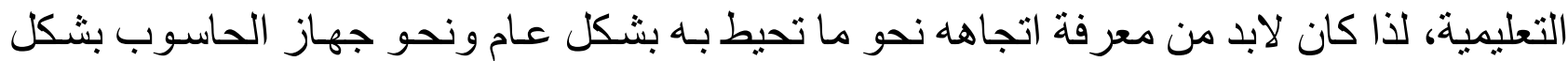

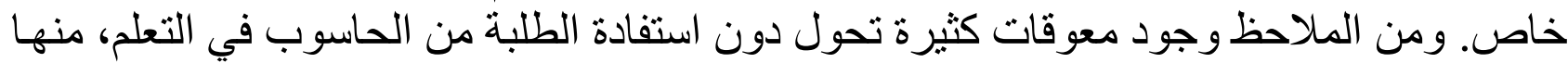

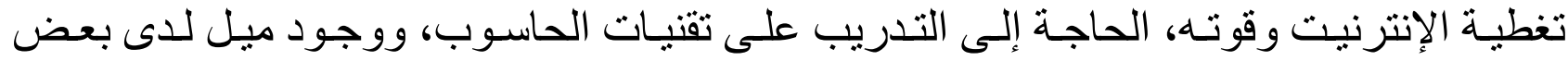

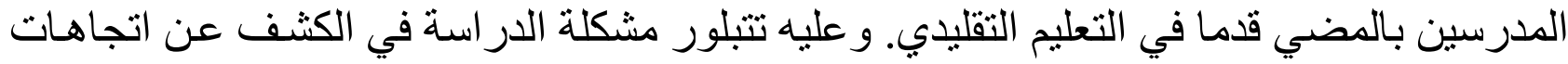

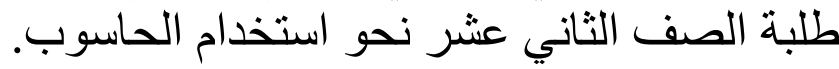

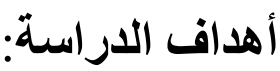
أ. تشخيص اتجاهات طلبة الصف الثاني عشر نحو استخدام الحاسوب.

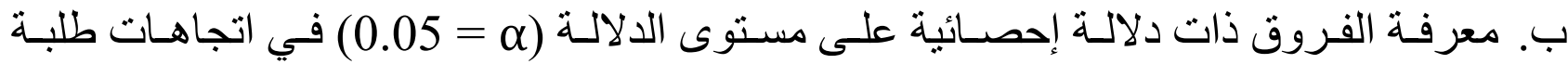
الصف الثاني عشر نحو استخدام الحاسوب تعزى لخبر اتهم في الحاسوب، وتلقي دورة سـابقة في

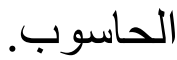

الاطار النظري والدراسات السابقة الإطار النظري

ميزات الحاسوب و إمكاناته التعليمية 


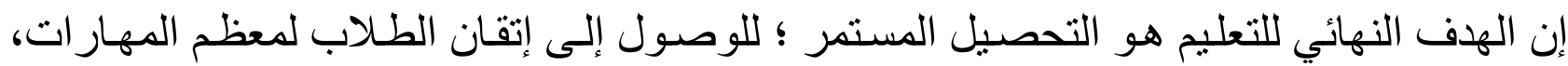

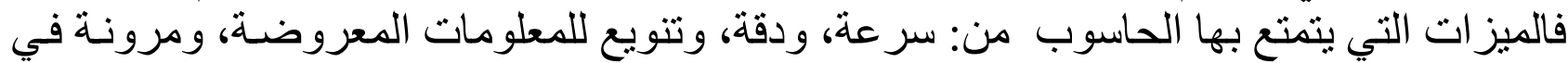

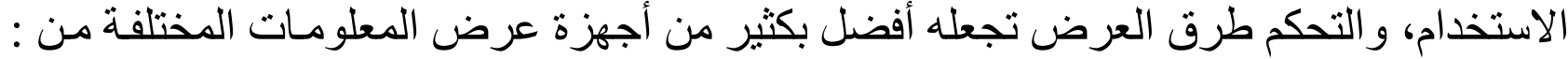

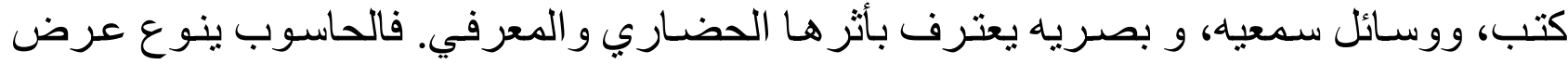

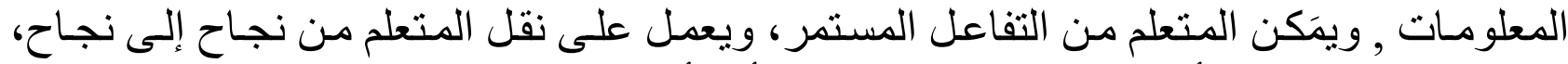
و هذا ما يطمئن المتعلم أثناء التعلم بالبرنامج وفيما يأتي أهم ميز ات استخدام الحاسوب في التعليم

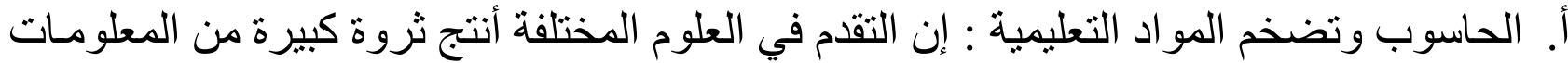

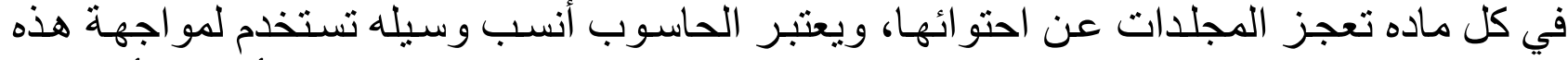

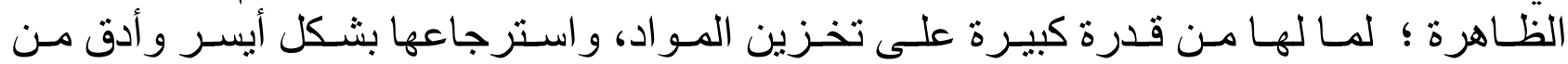

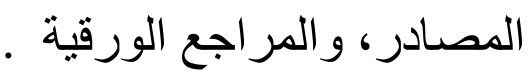

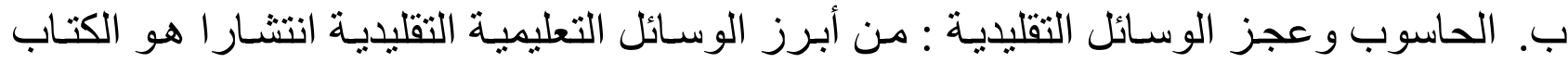

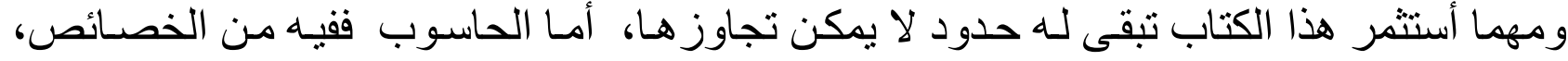

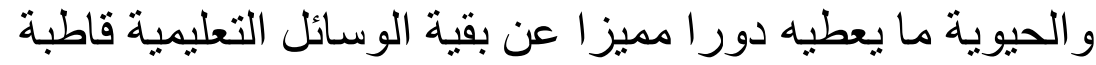

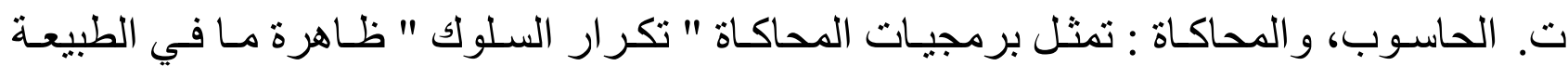

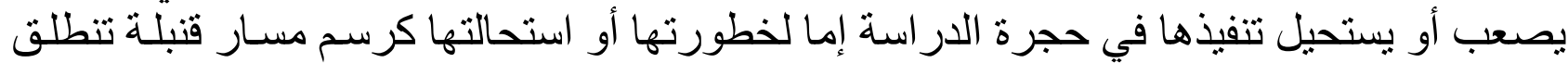

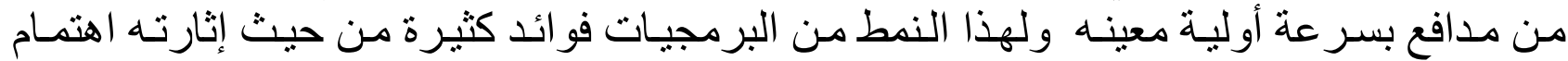

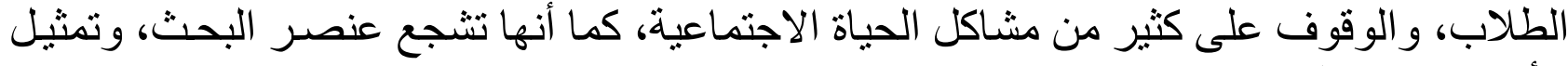

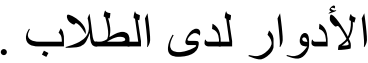

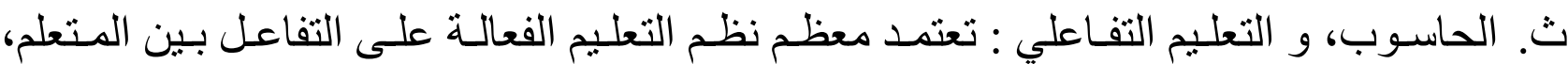

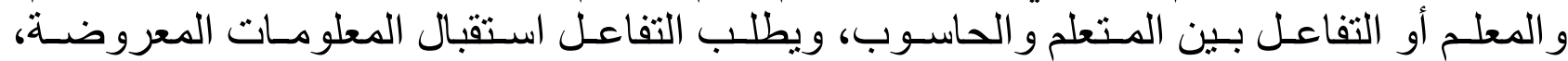

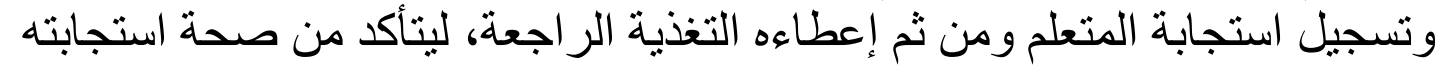

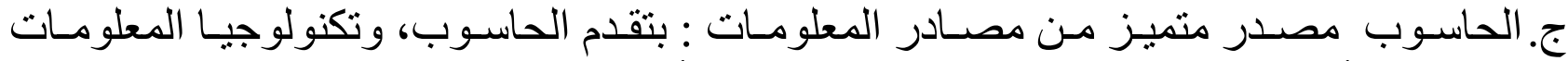

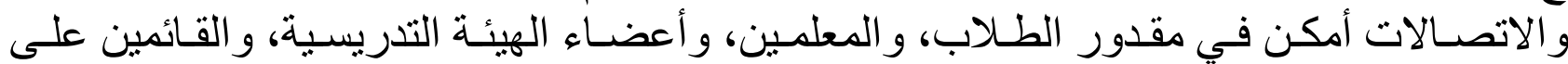

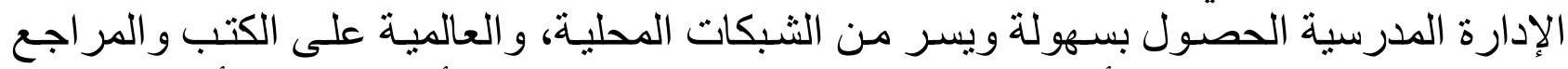

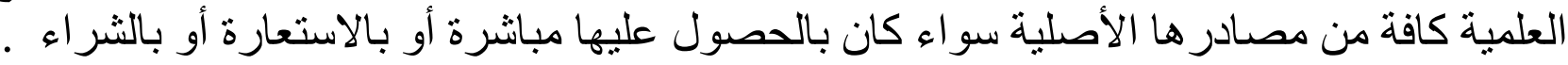

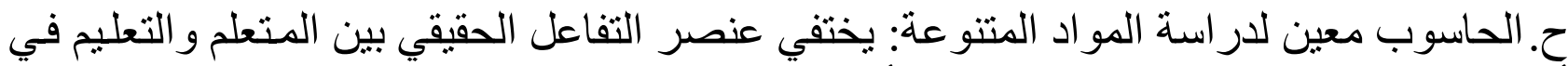

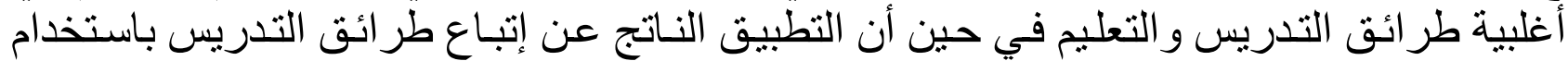

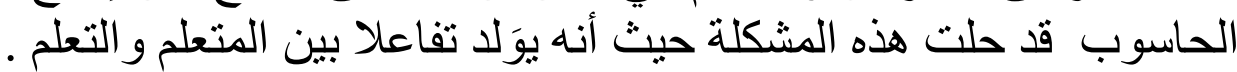

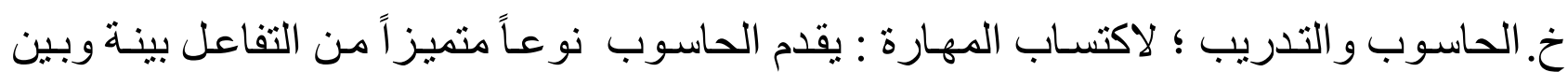

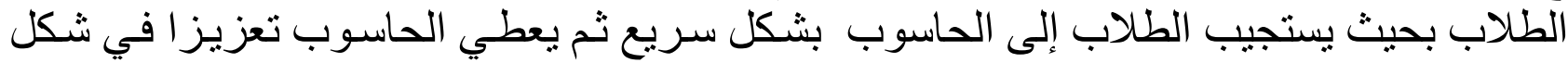

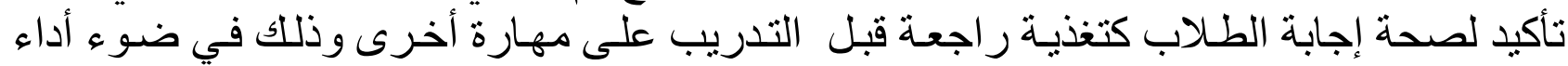

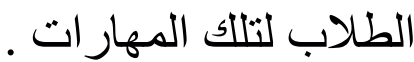

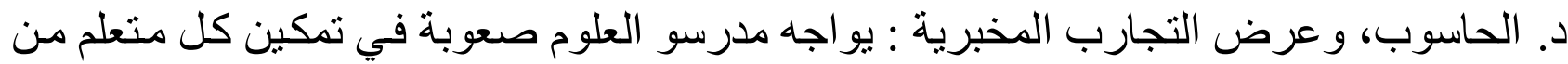

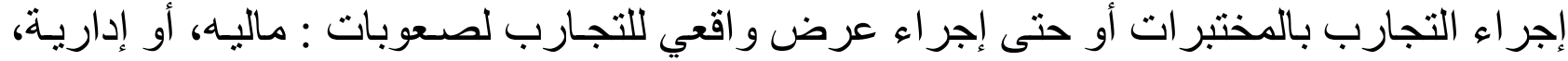

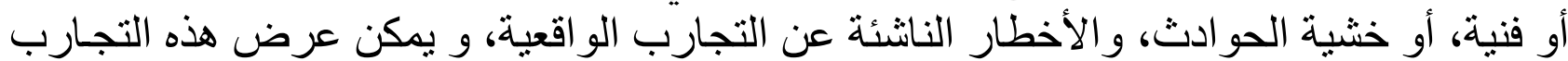




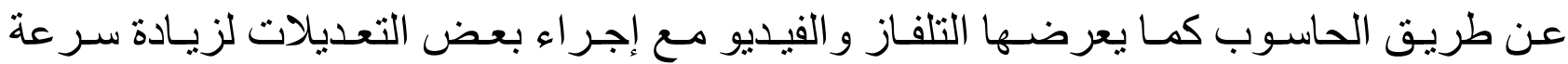

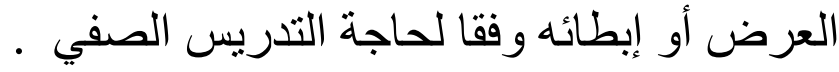

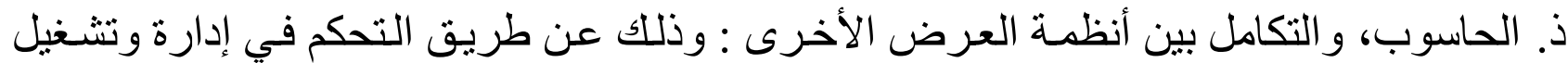

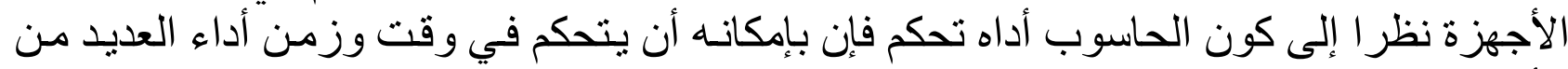

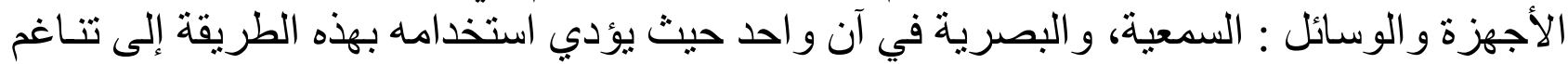
وتكامل تلك الوسائل و الأجهزة في خدمة الوالية العملية التعليمية .

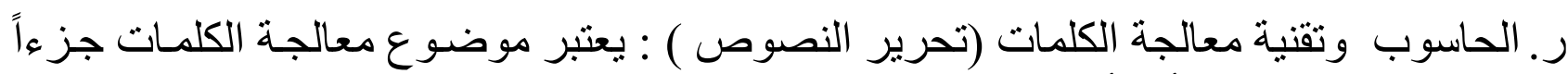

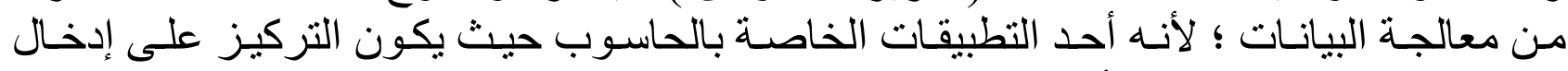

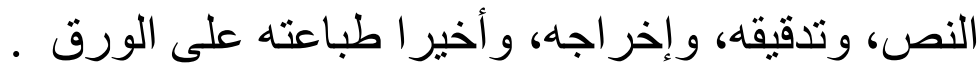

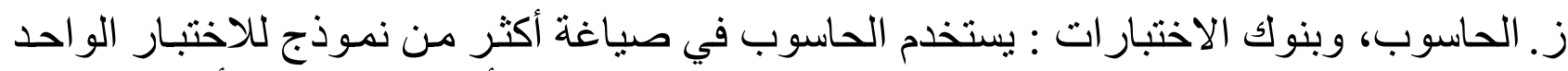

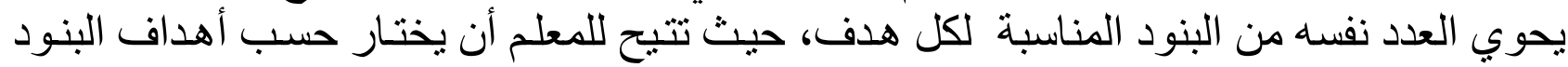

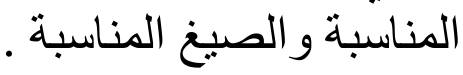

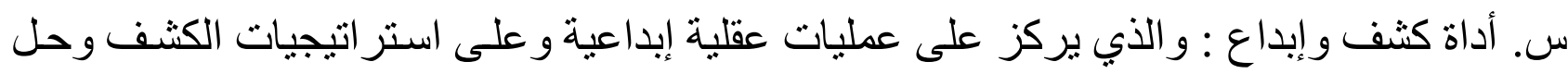
المشكلات التي دعا إليها "ديوي" و و "بياجيه" و وروجرزئ

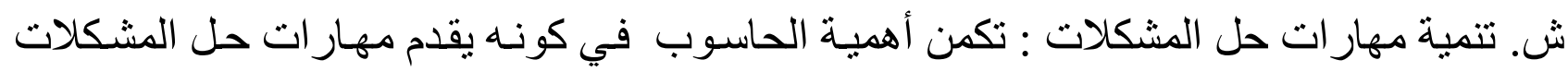

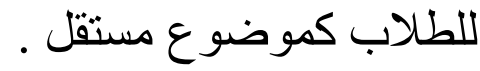

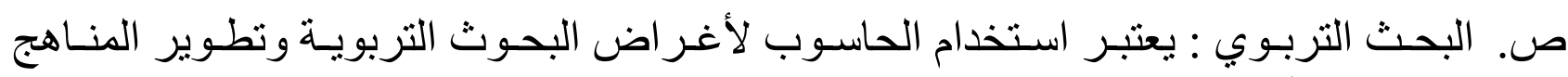

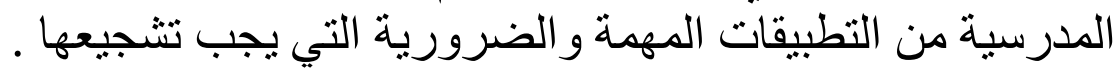

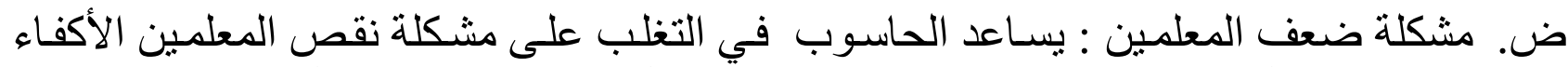

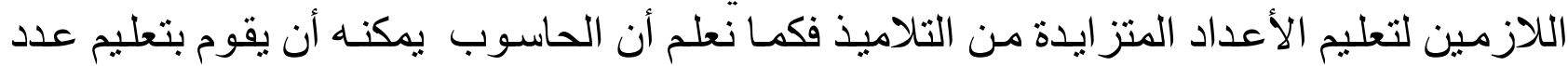

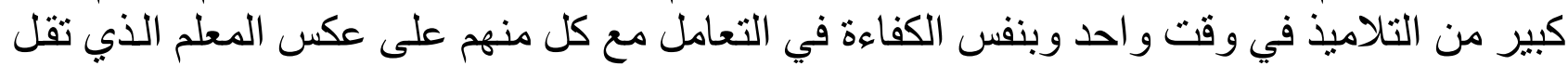

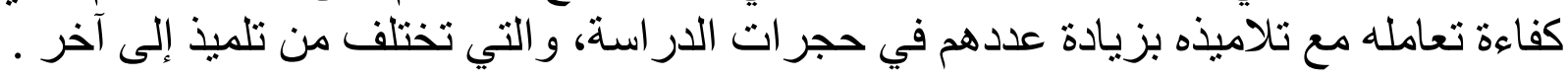

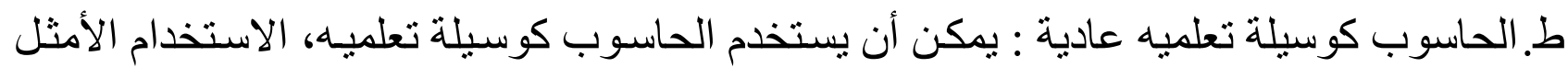

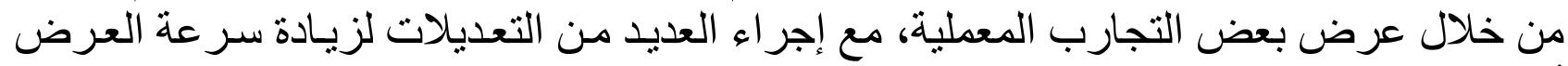
أو إبطائه وفقا للحاجة.

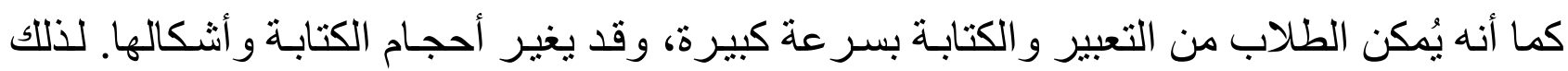

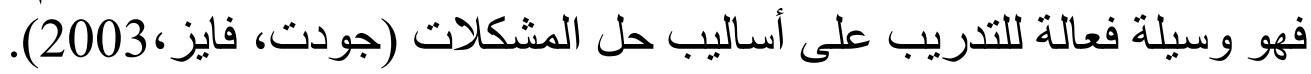
مجالات استخدام الحاسوب في التعليم : فيما يلي بعض الخدمات التي يمكن للحاسوب تقديمها في عدد من المجالات التربوية : أ. الحاسوب في خدمة المتعلم : حيث إن الحاسوب قد قطع شوطا كبير ا في خدمـة المتعلم بتوفير

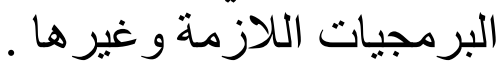

ب. الحاسوب في خدمة المعلم : فلقد أصبح الحاسوب أداة معينة للمعلم تسـاعده على القيام بو اجبـة و إعداد المعلومة وتقديمها لطلابه . 
ت. الحاسوب في خدمة أغراض التدريب : حيث بمكن استخدام الحاسوب في تدريب المعلمين ونقل الو اقع بالصوت و الصورة الصورة .

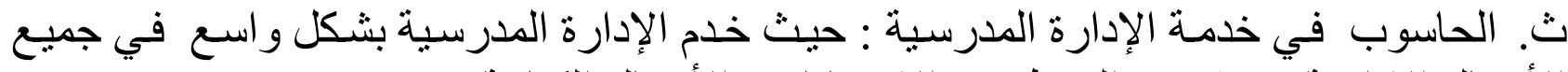

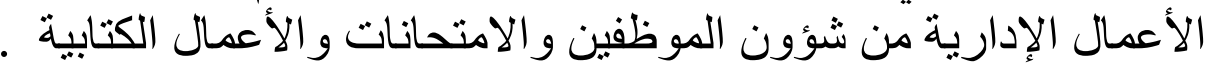

ج. الحاسوب في خدمة مطوري المناهج : لما كان هدف مطوري المنـاهج تحويـل المواد المدرسية المنهجية إلى برمجيات تعليمية تدرس بالحاسوب لهذا كان للحاسوب شأن كبير في تطوير المنـاهج في المستقبل .

ح. الحاسوب في خدمـة و اضـعي السياسـات التربويـة : حيـث أنها تقدم الخدمات للأنشطة الجاريـة ومستخلصات البحوث و الوثائق لمتخذي القرار ومطوري المناهج والباحثين . .(إبر اهيم، 2002) .

\section{الحاسوب كوسيلة تعليمية}

\section{الأهداف العامة لاستخدام الحاسوب كوسيلة تعليمية :}

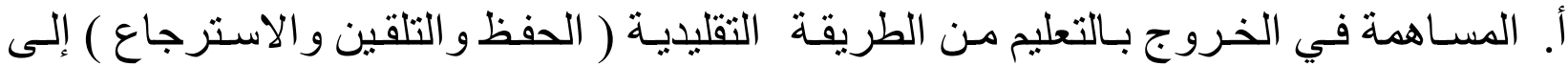
إكساب الطالب مهار ات التحليل المنطقي، وحل المشكلات وتتمية القدرات على التخطيط و اتخـاذ القرار.

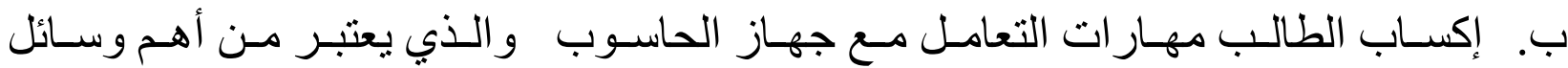

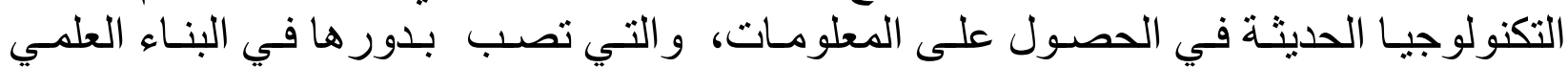
و الثقافي للطالب.

ت. إكساب المعلم مهار ات التعامل مع جهاز الحاسوب، و الخروج بـالتعليم من الطرق التقليديـة

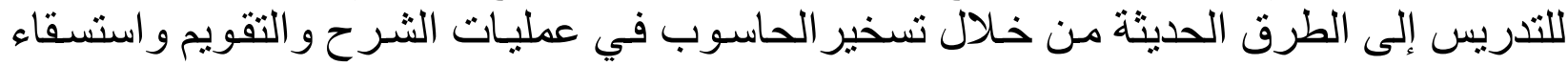
المعلو مات من مصسادر ها المختلفة.

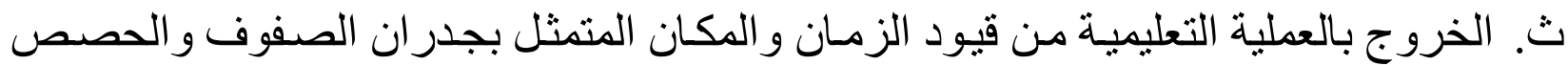
الدر اسية إلى فضـاء أكثر رحابـة ومتعـة من خلال الامتداد بـالتعليم ؛ ليمثل أحد الأنشطة الحيـة

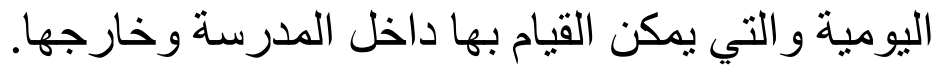

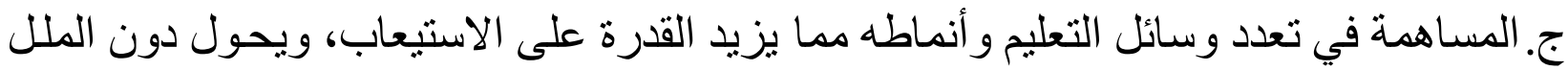
الذي يورثيه النمط الو احد و الطريقة الودئة الو احدة.

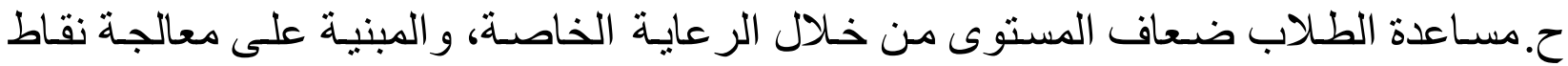
الضعف و المستويات المختلفة للطلاب من خلال البر امج المساعدة في العلوم المختلفة. خ. الارتقاء بالطلاب الجيدين خارج حدود المنهج، ومساعدتهم على النمو والتطور المعرفي. ومن خلال هذه الأهداف العامة التي يحققها استخدام الحاسوب كوسيلة تعليمية تنبئق العديد من الأهداف الجزئية منها: أ. تشجيع طرق التفكير الإبداعي، و البحث، و الاستقصاء عند المتعلمين . 
ب. تتمية مهارة حل المشكلات وأسلوب تقويم المعلومات وتحليلها .

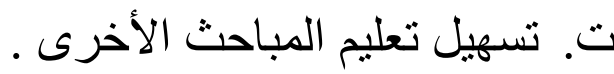

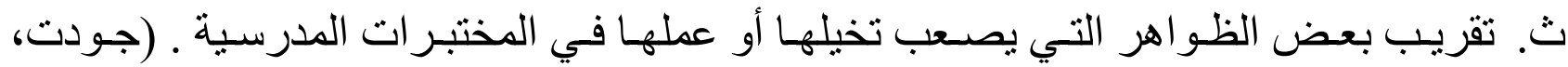
فايز، 2003). تصني

\section{مجالات استخدام الحاسوب كوسيلة تعليمية : مانية}

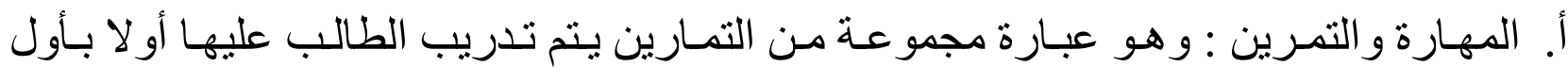

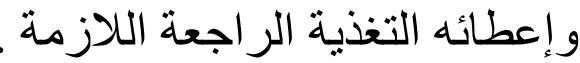

ب. الثرح و الإيضـاح : هذه البر امج من شروحات و إيضـاحات للهـادة العلمية المقرر تدريسها مـع إير اد الأمثلة عليها . الإن.

ت. الحوار التعليمي : ويعتمد هذا الأسلوب على الحوار الإر بين الجهاز والطالب حيث يقوم الجهاز

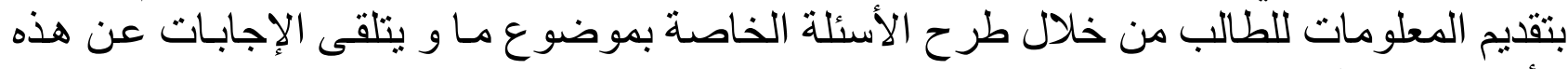

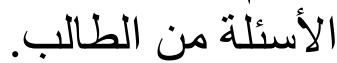

ث. المحاكاة : حيث يستخدم هنا لمحاكاة الظواهر الهر الطبيعيـة والتجارب التي يصـعب تحقيقها عمليا

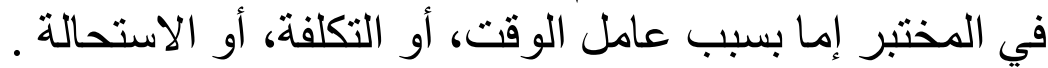

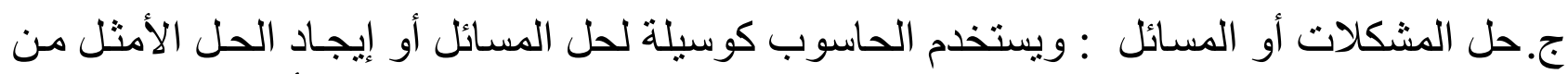

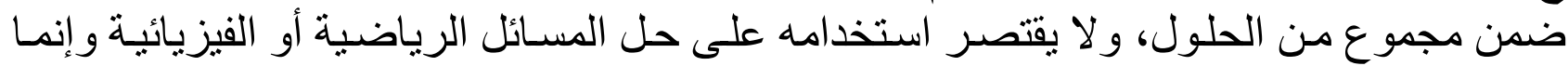

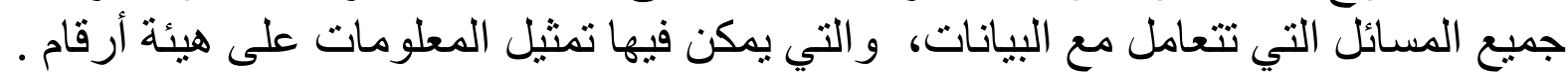

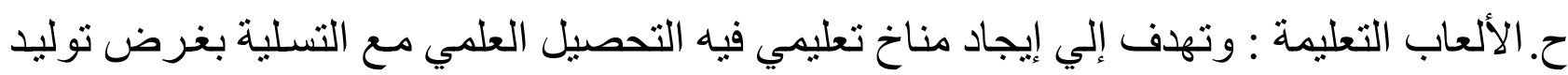

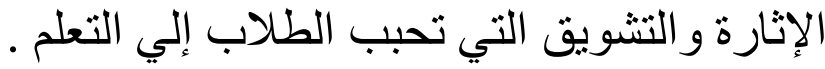

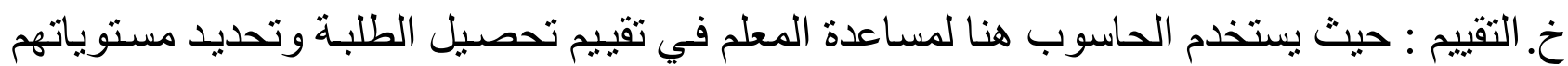
و التعرف إلى نقاط القوة و الضعف لديهم بطريقة فاعلة وسريعة توفر الوقت و الجهر .

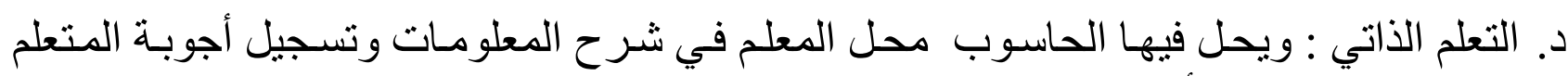

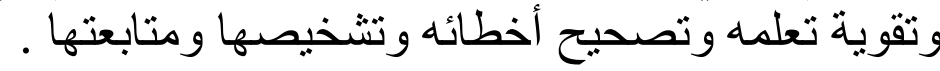

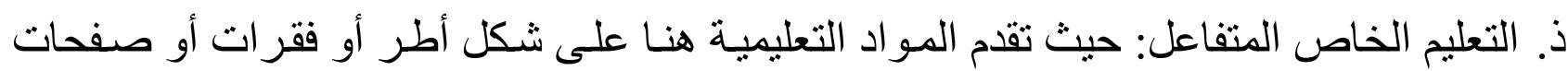

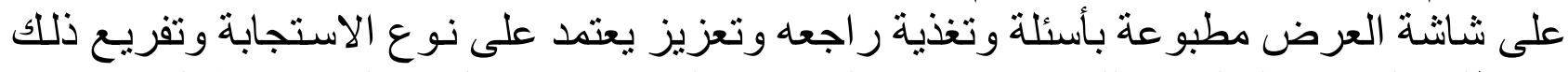

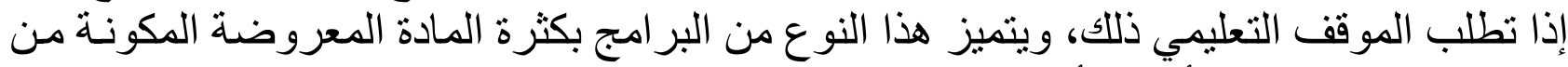

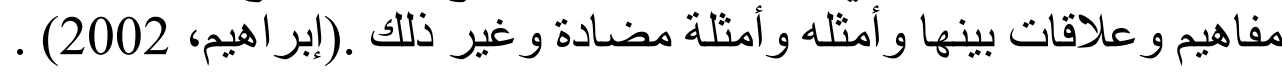
أهم برامج الحاسوب المستخدمة عالميا في التدريس:

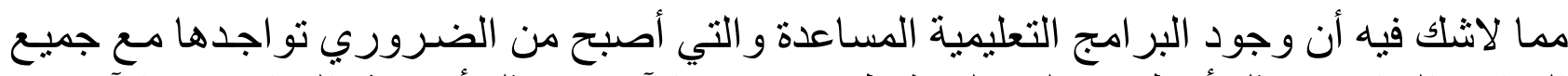

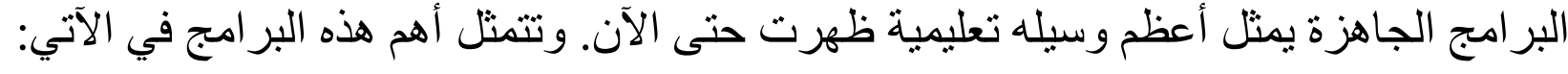

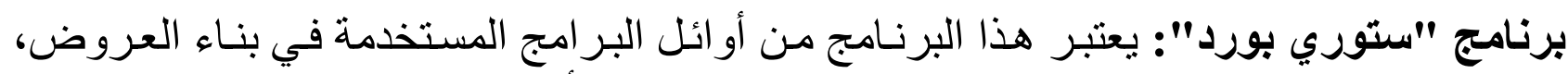

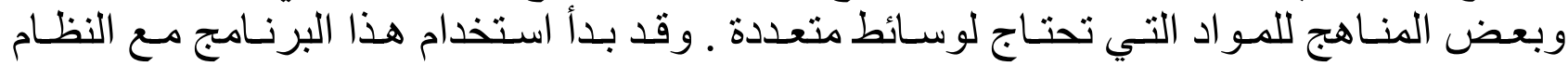




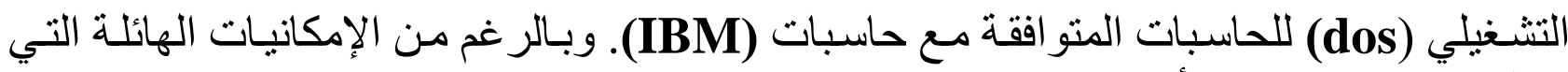

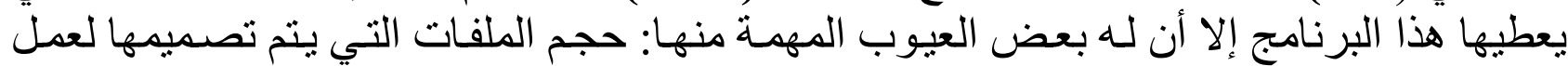

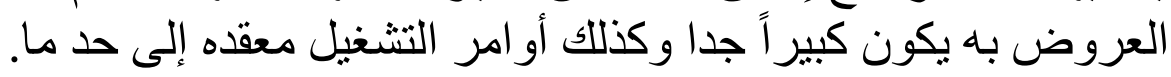

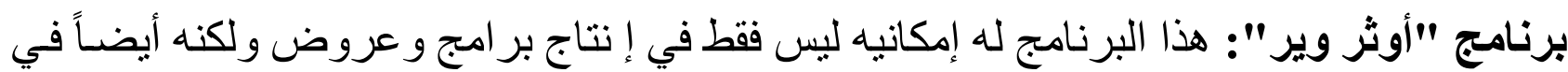

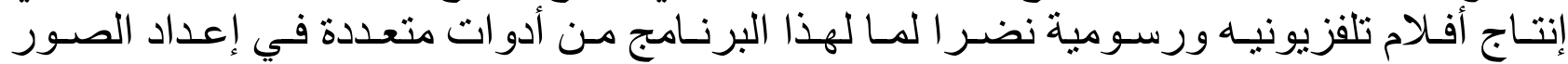

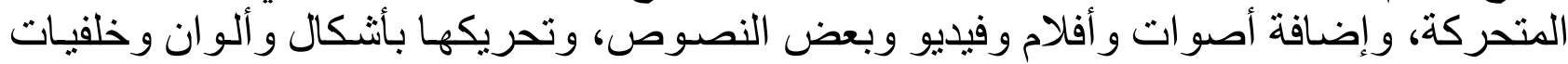

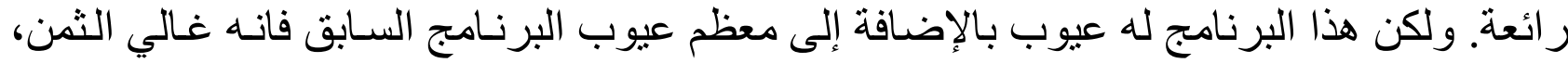

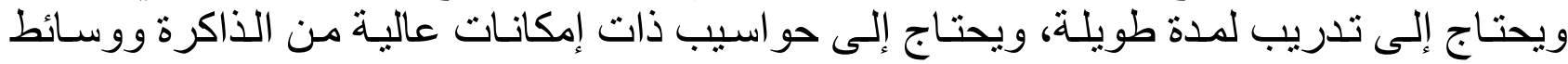

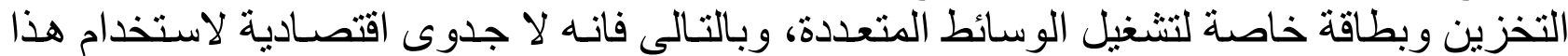
البرنامج كمرشح؛ ليكون أداة تنفيذ مناهج تعلمية.

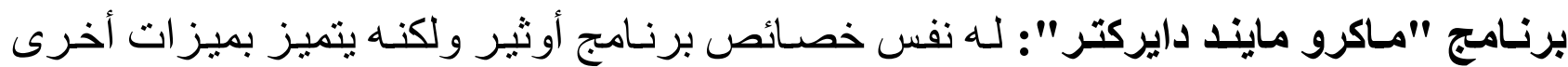

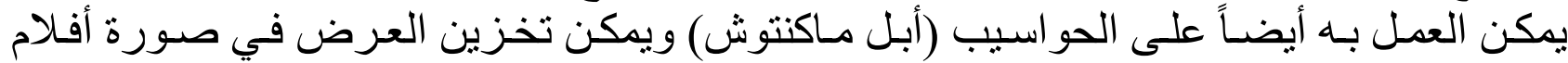

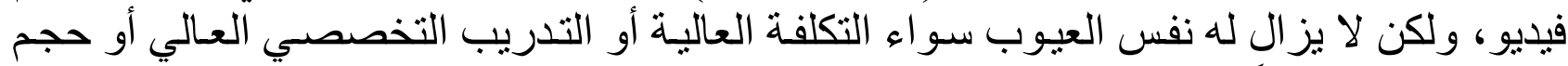
الملفات الكبير نسبياً، وكذلك عدم إمكانية تداول هذا النوع من الملفات النات خلال شبكة الحو اسيب.

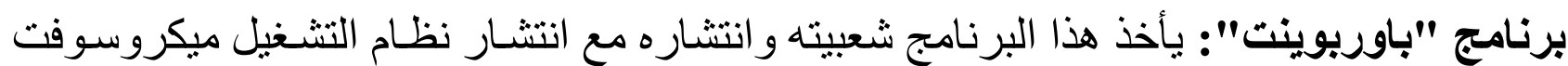

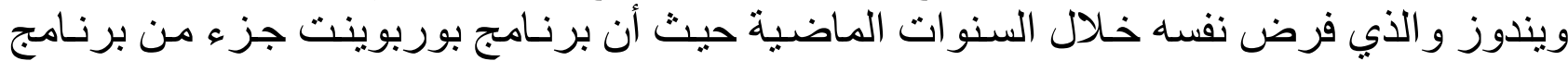

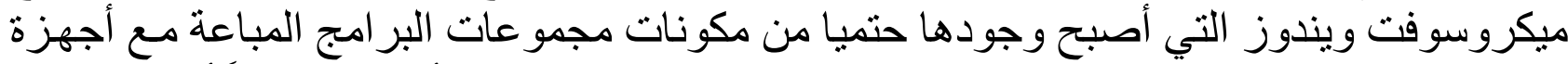

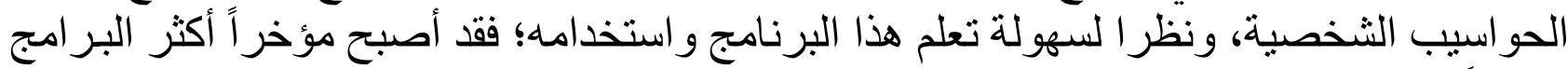

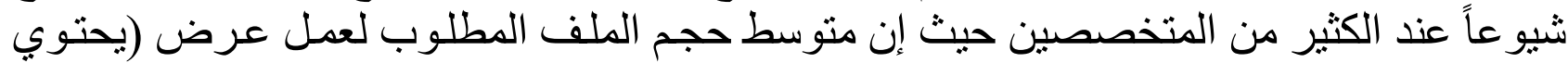
علي صوت وصورة) مدته نصف ساعة يتعدى عشرة (ميجابايت) (إبر اهيم، 2002).

إرشادات المعلم عند عمل أي وسيلة باستخدام الحاسوب: أ. توضيح الأهداف التعليمية المر اد تحقيقها .

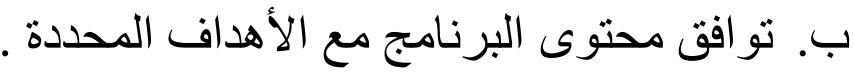

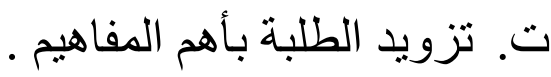
ث. ت تسلسل المحتوى منطقياً. تروئ. ج.وضوح كتابة النص وتقسيمه إلي فقر ات بشكل مناسب. ح.تر افق المعلومات التي تقدم مع المهار ات المتعلمة . خ.تحديد الأنشطة التي سيقوم بها الطالب .

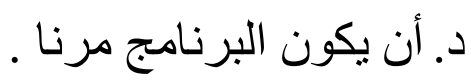
ذ. أن يخلق البرنامج تفاعلاً نشطاً. ر. أن تر اعي الخصائص الفنية وتشمل (البساطة ـ مناسبة مدتها الزمنية).

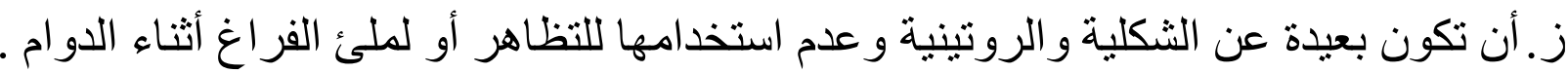




\section{س. أن تكون بعيده عن الحشو.(إبر اهيم القيروتي، 2002)

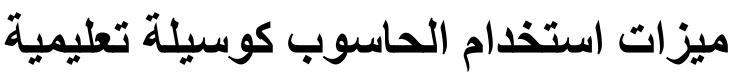

يمكن ذكر أبرز ميزات استخدام الحاسوب كوسيلة تعليمية في الآتي :

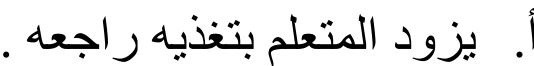

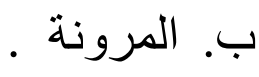

ت. ت التشويق .

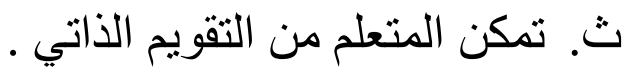

ج. ينمي مفهوم إيجابي للمتعلم .

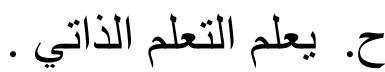

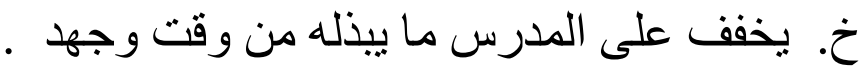
د. تقليل زمن التعلم وزيادة التحصيل .

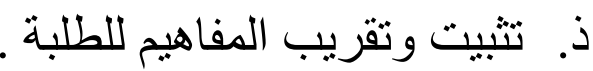

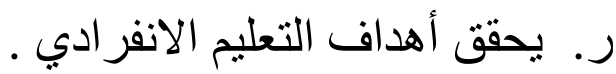

ز. يتعلم الطالب بالسر عة التي تناسب قدر اتهـ.

س. يعرض المادة التعليمية بشكل منظم ومقنن.

عوائق استخدام الحاسوب كوسيلة تعليمية

أهم العوائق التي تحد من استخدام الحاسوب كوسيلة تعليمية :

أ. التكلفة المادية.

ب. ب. المشاكل الفنية. .

ت. اتجاهات المعلمين نحو استخدام التقنية (العزوف، الجهل باستخدام الحاسوب، اللغة).

عوامل نجاح الحاسوب في العملية التعليمية

ويعتمد نجاح الحاسوب في العملية التعليمية يعتمد على عدة عو امل من أهمها :

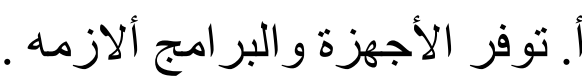

ب. كفاءة المعلمين والمرونة في التعامل ؛ لتفعيل فكرة الحاسوب في إعداد الوسائل التعليمية . ت. توفير الحوافز والدعم للمدارس التي يستخدم فيها الحاسوب في إعداد الوسائل . واقع استخدام الحاسوب في العملية التعليمية في سلطنة عمان

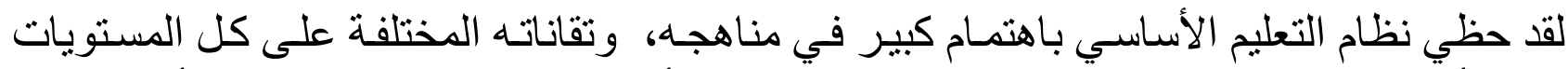

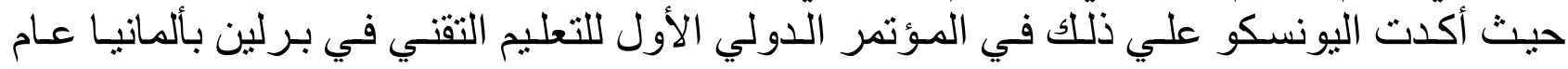

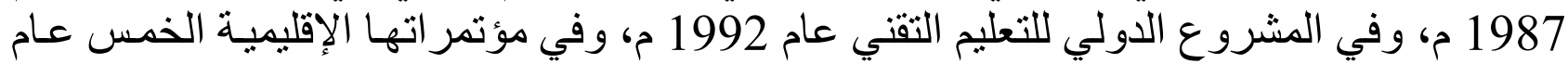




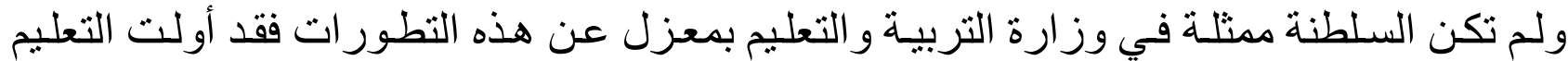

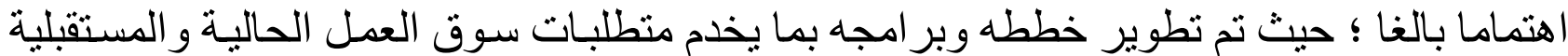

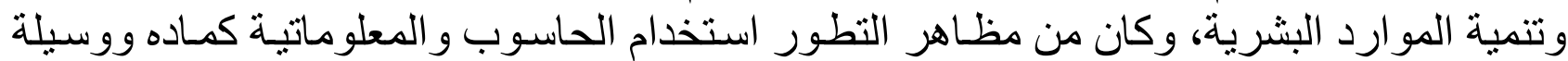

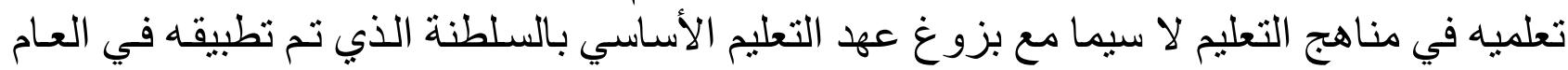

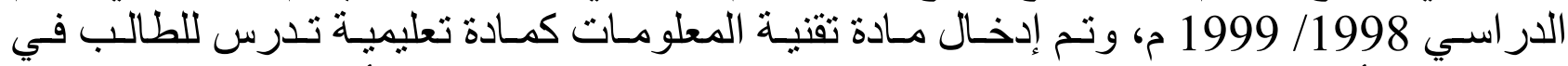

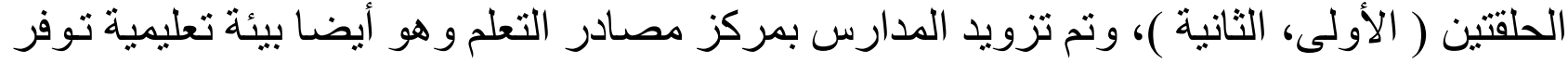

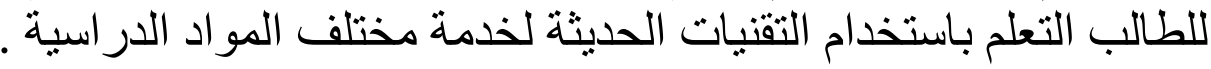

الار اسات السابقة:

دراسات سابقة في مجال استخدام الحاسوب كوسيلة تعليمية

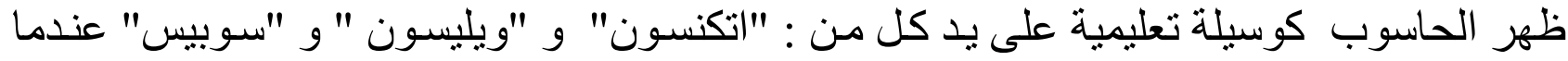

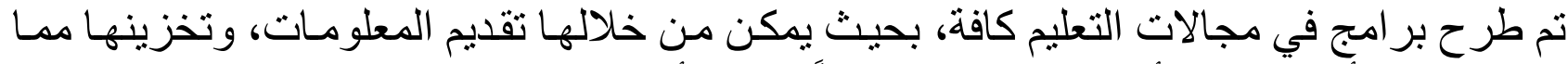

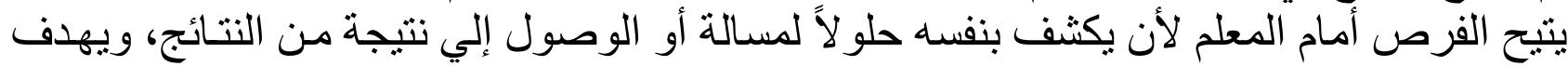

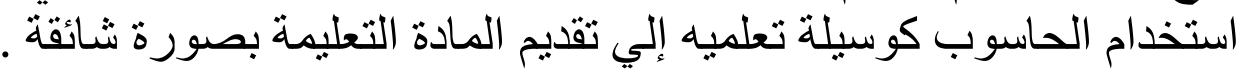

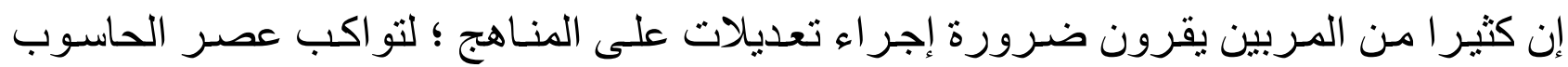

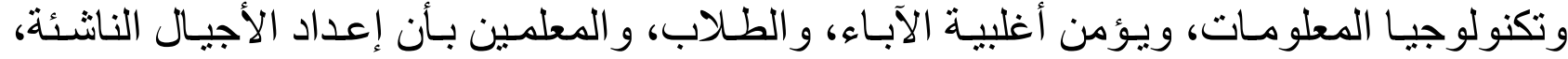

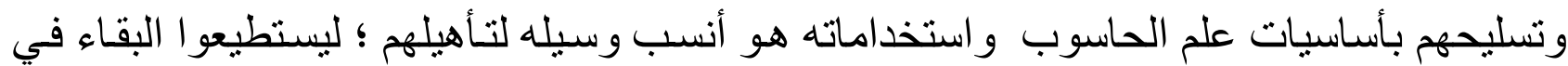

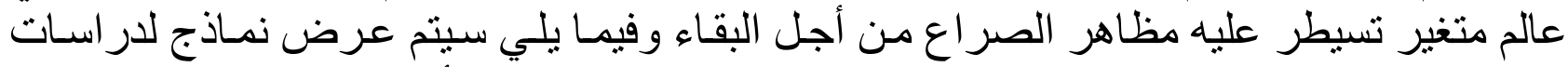

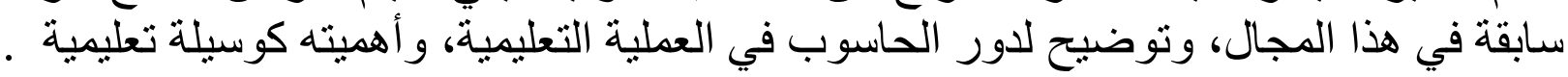

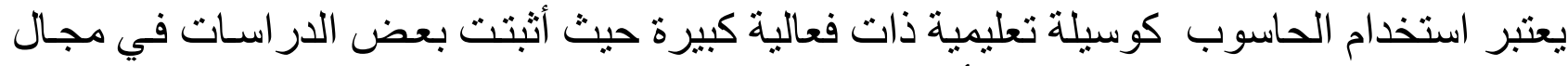
الحاسوب و التعليم هذه الفاعلية، حيث أدى استخدام الحاسوب كوسيلة تعليمية إلى تحقيق الآتي :

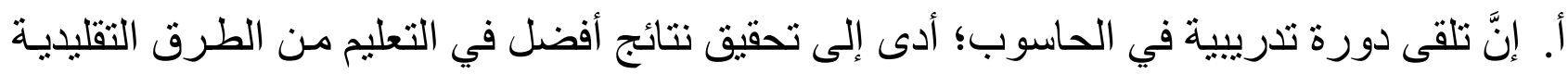

ب. توفير بعض الوقت في التعليم مقارنة بالوقت العادي للكمية ذاتها من المادة التعليمية .

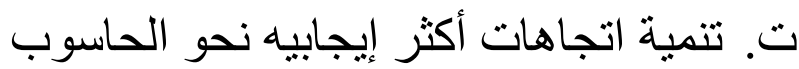

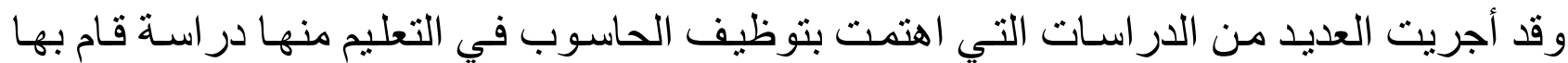

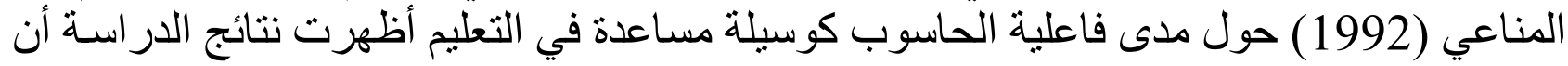

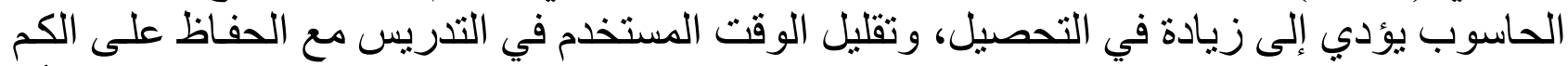

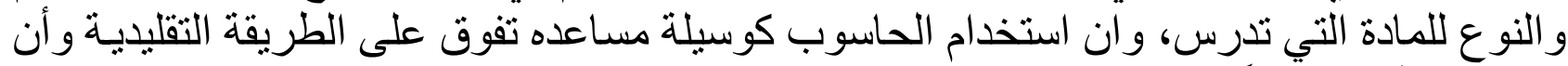

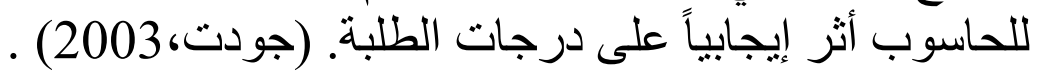

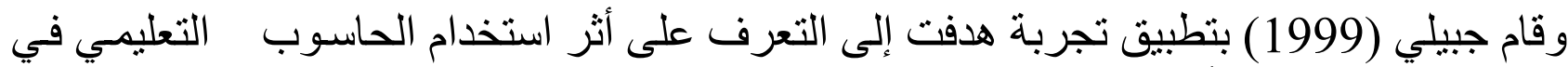

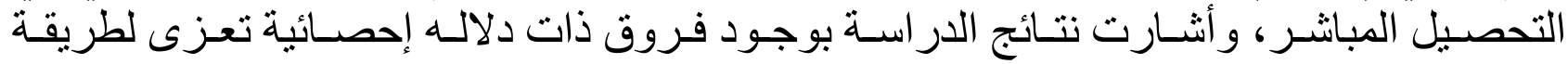
التدريس لصالح الحاسوب التعليمي . 


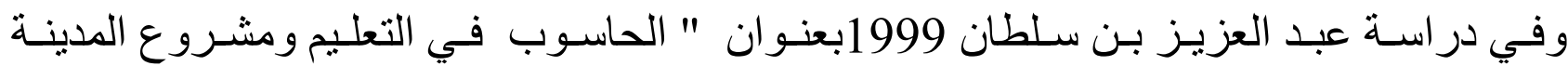

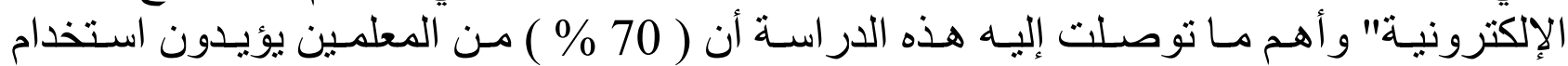

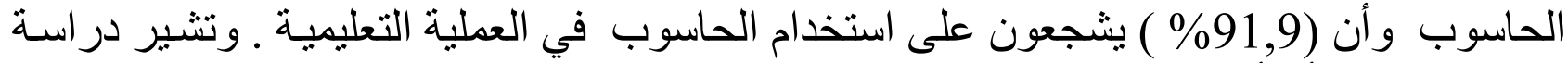

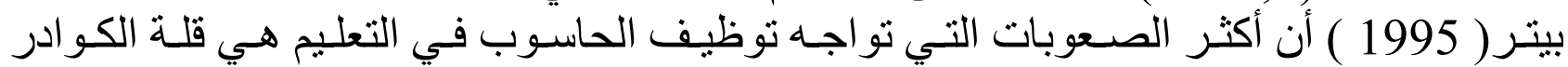

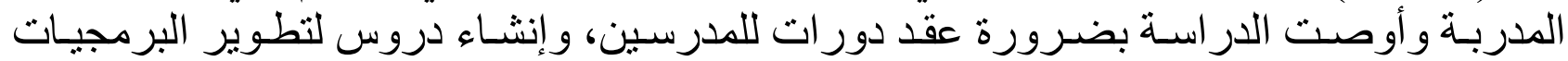

\section{أهم ما توصلت له الاراسات السابقة في مجال استخدام الحاسوب كوسيلة تعليمية}

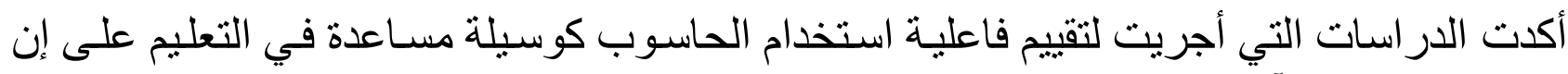
الحاسوب يحقق الآتي: - الآي

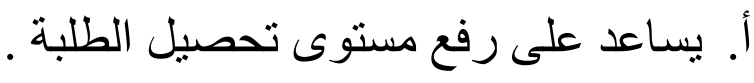

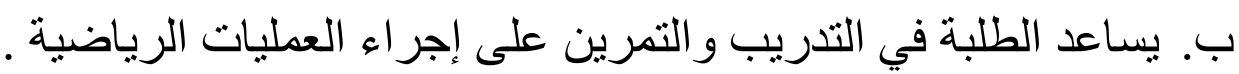

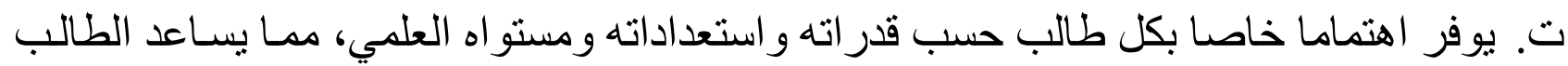

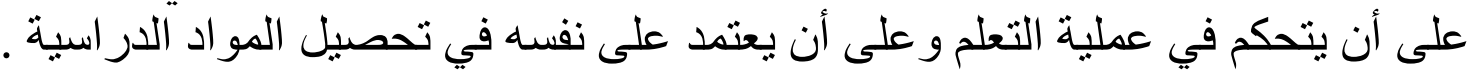

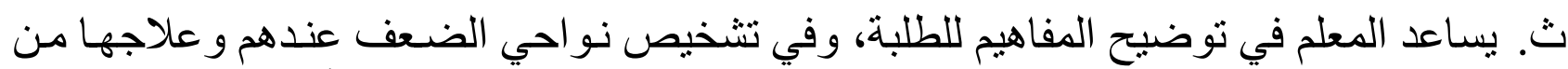

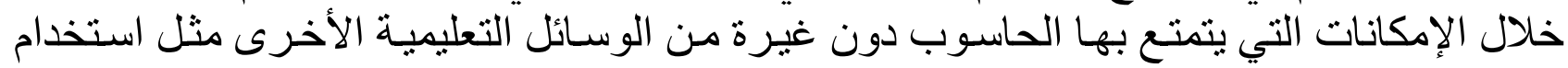

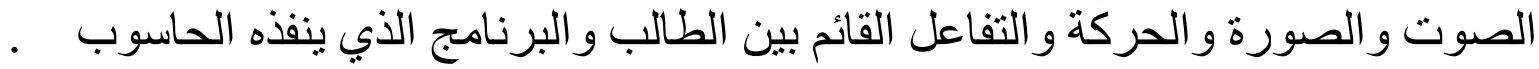
ج.يؤثر إيجابيا في تعليم الطلبة الذين يعانون من صعوبات في التعليم في تحصيلهم واتجاهاتهم نحو

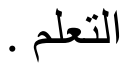

ح.يساعد الطلبة على تتمية مهارة حل المشكلات وتتمية التفكير المنطقي لديهم (إبر اهيم، 2002). الطريقة والإجراءات: - ماتمات اعتمد الباحث المنهج الوصفي التحليلي. و اعتمد المنهج الكمي في جمع البيانات.

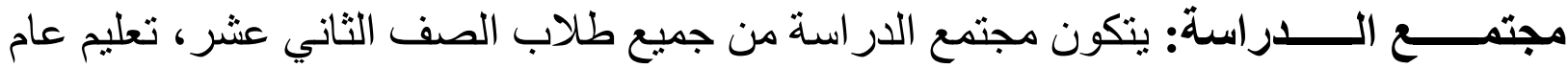

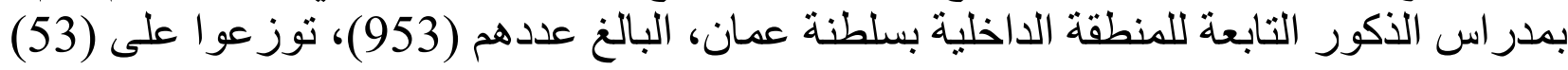
شعبة صفية في (8) مدارس.

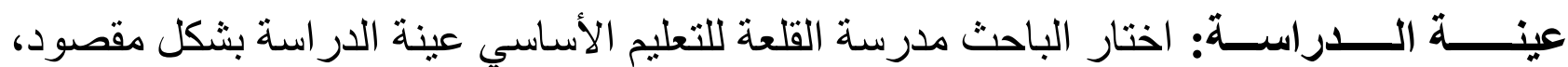

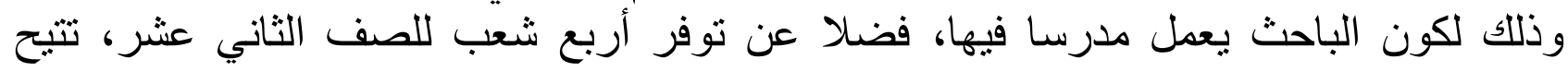

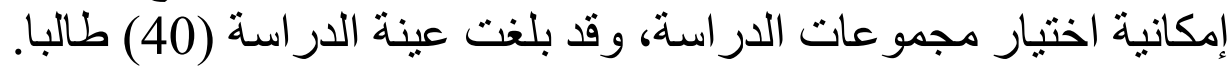

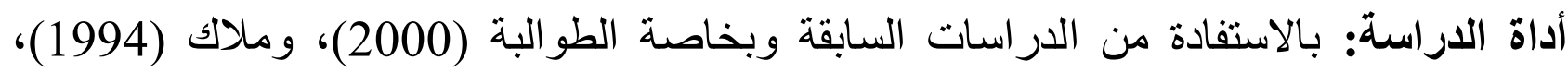

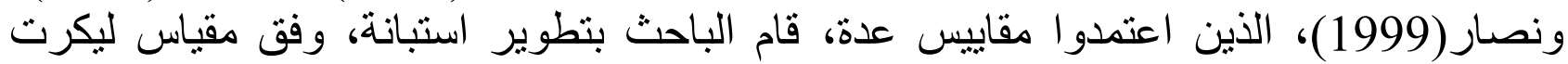

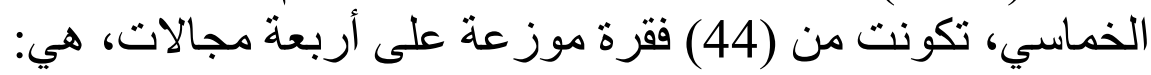

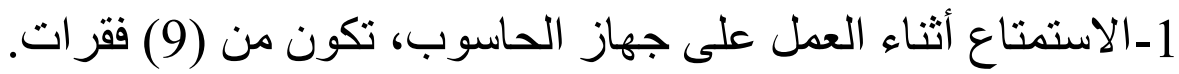


2-الخوف و القلق عند استخدام الحاسوب تكون من (9) فقرات.

3-المشاعر نحو الحاسوب تكون من (15) فقرة.

4-فائدة الحاسوب تكون من (9) فقر ات.

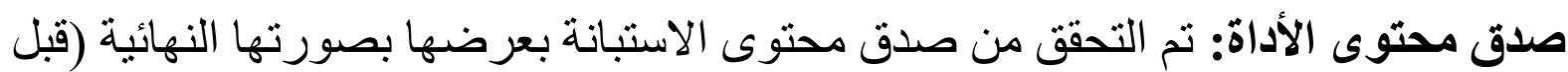

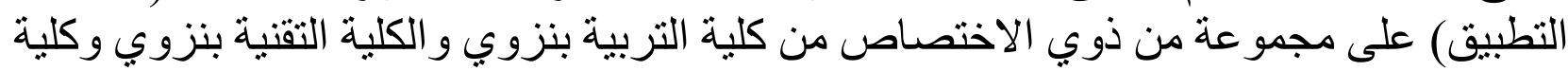

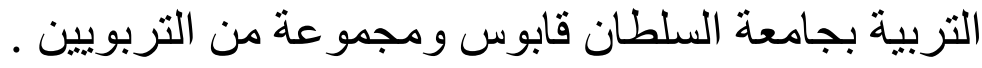

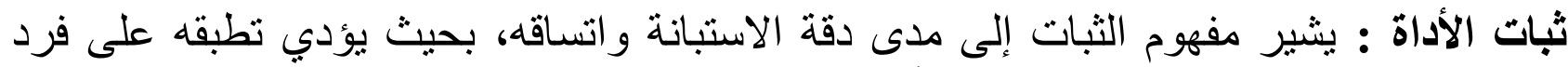

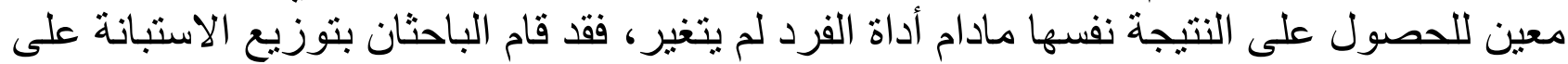

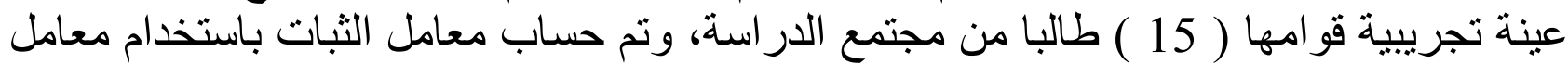

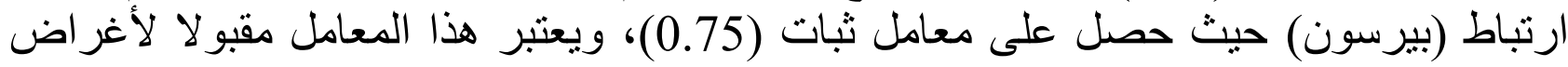
البحث العلمي.

\section{المعالجات الإحصائية:}

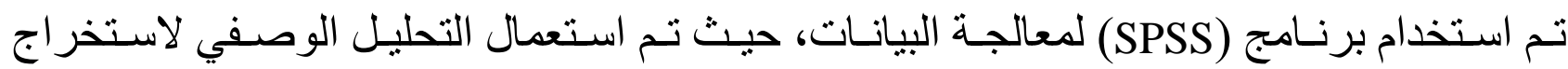

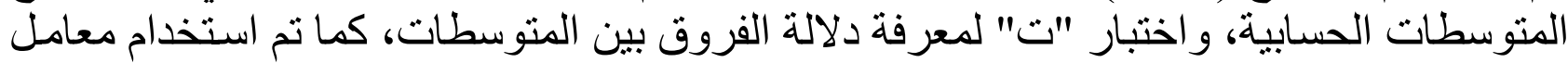

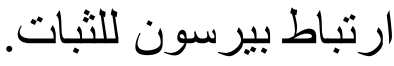
نتائج الدراسة ومناقثتنها:

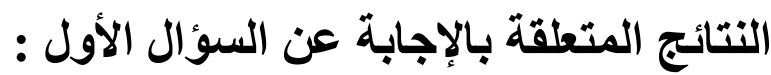

س1: ما اتجاهات طلاب الصف الثاني عشر من التعليم الأساسي نحو استخدام الحاسوب؟

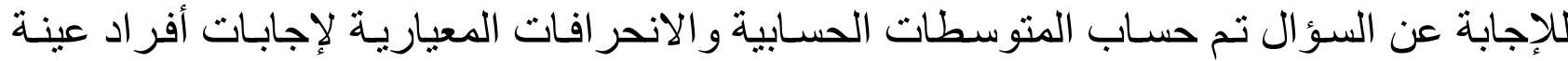
الدر اسة، عن كل فقرة من فقرات الاستبانة، وكما موضح في الجدول الاست (1) الآتي:

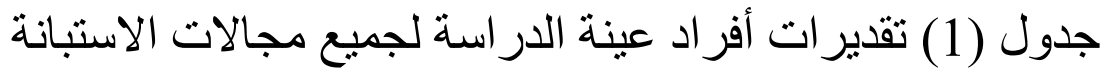

\begin{tabular}{|c|c|c|c|c|c|}
\hline المعياري & الحستوسي & الفقرات & 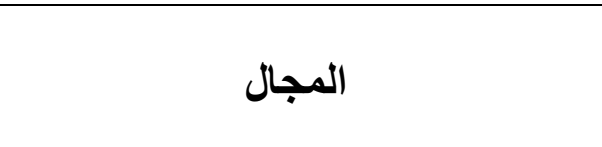 & الرتبة - الم & رالمجال \\
\hline 0.95 & 4.08 & 9 & الاستمتاع أثناء العمل بجهاز الحاسوب & 1 & 1 \\
\hline 0.87 & 3.77 & 9 & الخوف و القلق عند استخدام الحاسوب & 3 & 2 \\
\hline 1.13 & 3.45 & 15 & المشاعر نحو الحاسوب & 4 & 3 \\
\hline 0.74 & 3.42 & 9 & فائدة استخدام الحاسوب & 5 & 4 \\
\hline 0.923 & 3.68 & & معدل المحاور & & \\
\hline
\end{tabular}

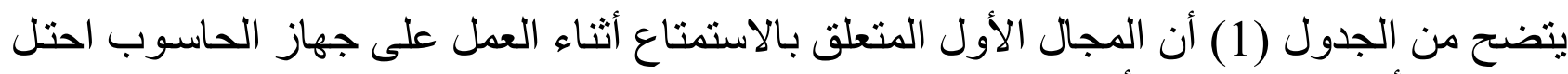

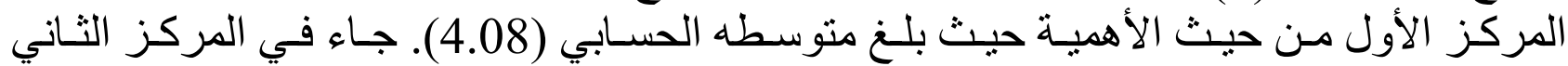


المجال الثاني و هو الخوف و القلق عند استخدام الحاسوب، حيث بلغ متوسطه الحسابي (3.77). أمـا

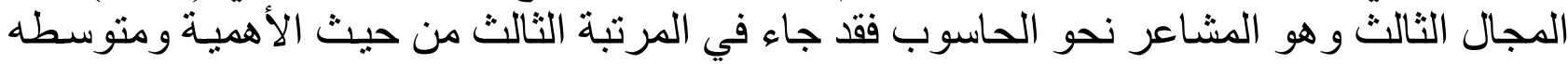

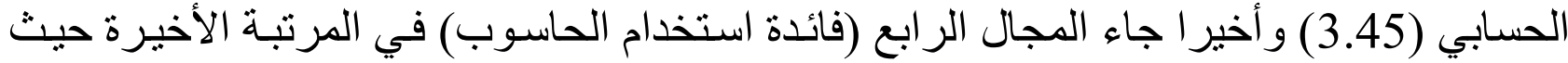
بلغ متوسطه الحسابي (3.42).

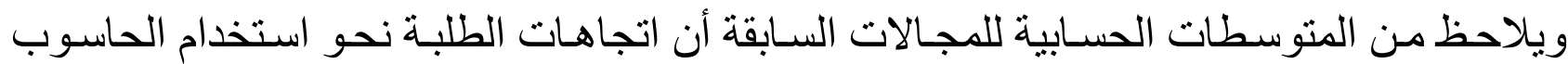
كانت إيجابية، حيث بلغ المتوسط الحسابي الكلي لمحاور الدراسة (3.68) أي بمستوى مرتفع.

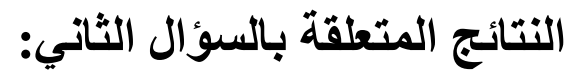

هل تختلف اتجاهـات طلبـة الثاني عشـر مـن التعليم الأساسـي نحو استخدام الحاسـوب بـاختلاف خبر اتهم السابقة؛ للإجابة عن السؤال تم التعامل مع كل فرع من فروعه على حدة وذلك من حيث: أ) دراسة مساق سابقا في مجال الحاسوب:

للكثف عن ذلك تم حساب المنوسطات الحسابية و الانحر افات المعيارية، وتم استخدام اختبار (ت) (ت)

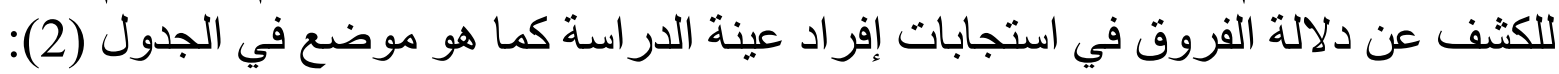

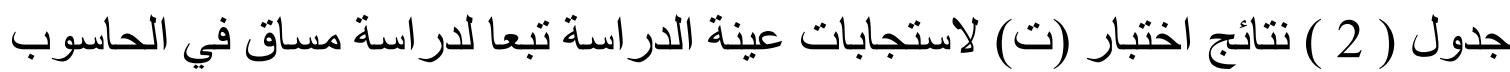

\begin{tabular}{|c|c|c|c|c|c|}
\hline مستوى & "المحسوبة " " " & الالتحرياري & المستوسط & العدد & درابة مساق \\
\hline \multirow[t]{2}{*}{0.00} & 0.63 & 0.50 & 1.77 & 36 & نعم \\
\hline & 0.56 & 0.57 & 1.66 & 3 & $y$ \\
\hline
\end{tabular}

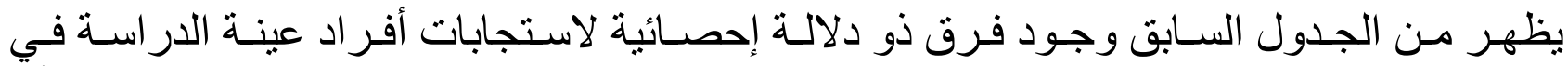

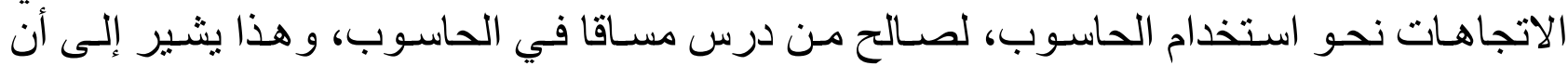

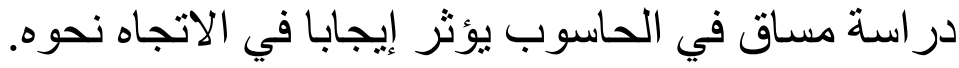
ب) تلقي دورة تلدريبية في الحاسوب:

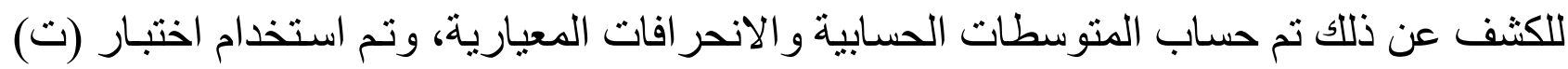

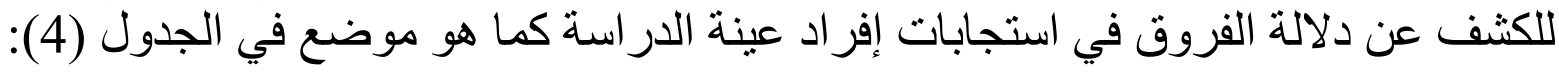

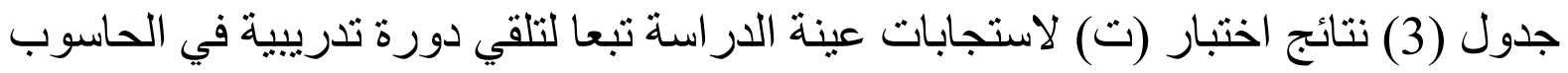

\begin{tabular}{|c|c|c|c|c|c|}
\hline مستوي & قالمحسوبة " ت " & الالحعراف & الحسابي & العدد & في الحّاسوب دورة \\
\hline \multirow[t]{2}{*}{0.00} & 4.35 & 0 & 1 & 10 & نعم \\
\hline & 7.61 & 0.47 & 1.6 & 30 & ע \\
\hline
\end{tabular}

ويظهر مـن الجدول السـابق وجود فرق ذو دلالتة إحصـائية لاستجابات أفر اد عينة الدر اسـة في 
الاتجاهات نحو استخدام الحاسوب، ولصالح من نلقى دورة تدريبية في الحاسوب، و هذا يشير إلى الى أن تلقي أي دورة تدريبية في الحاسوب يؤثر إيجابا في الاتجاه نحوه

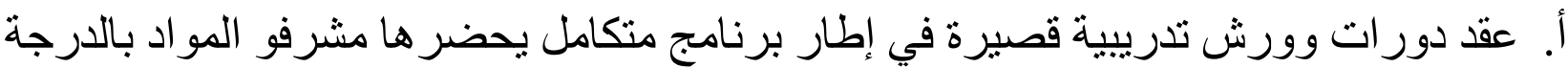

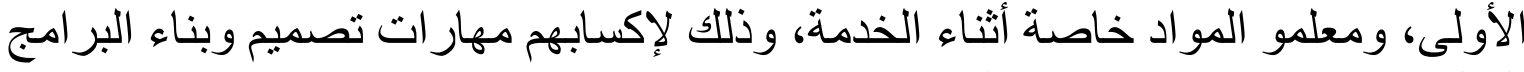

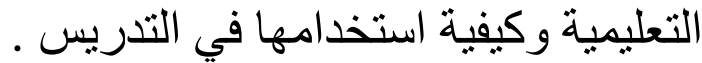
ب. تضمين بعض الوحدات الدر اسية موضو عات استخدام الحاسوب .

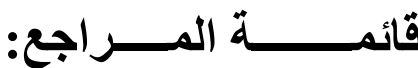

الحبيب، ححمد إبر اهيم، عبدالرحمن، ابتسام. (2002). دور مركز مصـادر التعلم في العملية التعليميـة و التربوية في دول الخليج العربية. الطبعة الثانية، البحرين: دار الحكمة الحمة. سـعادة، جـودت أحمـد، السـرطاوي، عـادل فـايز (2003) ـ "اسـتخدام الحاسـوب و الإنترنــت في في

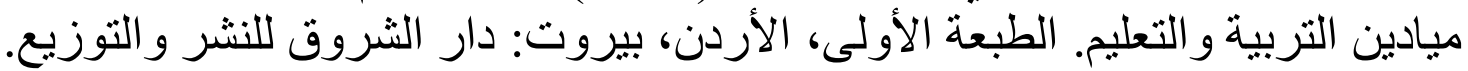
سبد، عبد الحليم (1995). الكمبيوتر في التعليم. القاهرة: عالم الكتب . عبيد، ماجدة السيد (2001) ."تصميم و إنتاج الوسائل التعليمية". الطبعة الأولى، عمـان: دار صفاء للنشر و التوزيع ماجيخ

الفار، إبر اهيم عبد الوكيل (1998). تربويات الحاسوب وتحديات مطلع القرن الحـادي و العثرين. الطبعة الأولى، القاهرة: دار الفكر العربي. (العي.

الفـار ، إبر اهيم عبدالوكيل (2002). اسـتخدام الحاسـوب في التعليم. الطبعـة الأولى، عمـان: دار الفكر للطباعة و النشر و التوزيع.

القريـوتي، إبـر اهيم أمسين (2002). إرشـادات للمعلم عند التعليم بواسطة الحاسـوب. العدد 165،

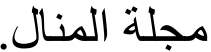

\section{ARABIC REFERENCES IN ROMAN ALPHABETS}

Alhabibu, Muhamad 'librahim, Eabdalrhmn, Aibtasam. (2002). Dawr Markaz Masadir Altaelum Fi Aleamaliat Altaelimiat Waltarbawiat Fi Dual Alkhalij Alearabiati. Altubeat Althaaniati, Albahrayna: Dar Alhakmat.

Saeadat, Jawadt 'Ahmad, Alsirtawi, Eadil Fayiz (2003) . "Astikhdam Alhasub Wal'iintarint Fi Miadin Altarbiat Waltaelimi. Altibeat Al'uwalaa, Al'urduni, Biruta: Dar Alshuruq Lilnashr Waltawzie. Syd, Eabd Alhalim (1995). Alkimibiutir Fi Altaelim. Alqahrt: Ealam Alkutub .

Eubayd, Majidat Alsyd (2001) ."Tsmim Wa'iintaj Alwasayil Altaelimia". Altabeat Al'uwlaa, Eaman: Dar Safa'an Lilnashr Waltawzie .

Alfari, 'librahim Eabd Alwakil (1998). Tarbawiaat Alhasub Watahadiyat Matlae Alqarn Alhadi Waleishrina. Altibeat Al'uwalaa, Alqahrt: Dar Alfikr Alearabi.

Alfaru, 'librahim Eibdalwkil (2002). Aistikhdam Alhasub Fi Altaelimi. Altibeat Al'uwalaa, Eamana: Dar Alfikr Liltabaeat Walnashr Waltawzie.

Alqaryuti, 'librahim 'Amin (2002). 'lirshadat Lilmuelim Eind Altaelim Bwastt Alhasub. Aleadad 165, Majalat Almanal. 